LIAMES, Campinas, SP, v. 20, 1-39, e020008, 2020

\title{
Motivos contenidos en narraciones tradicionales orales de los kari'ña, pemón y ye'kwana.
}

\author{
Andrés Romero-Figueroa \\ Universidad Católica Andrés Bello, Venezuela \\ anromero@ucab.edu.ve \\ https://orcid.org/0000-0002-9788-170X
}

\begin{abstract}
The ethnological matters dealt with in this paper are concerned with three North Carib groups ---Kari'ña, Pemon and Ye'kwana--- all of them settled within Venezuelan boundaries. The aim has been to index those lexical items representing "motifs" (Motif-Index of Folk-Literature, Stith Thompson 1955-1958) within oral tales by means of which traditions are passed on from one generation to the next. Thompson (1946) defines "motif" as "[...] the smallest element in a tale having a power to persist in tradition. In order to have this power it must have something unusual and striking about it" (pág. 415). The compiled motif-index, or MI, comes from 8 tales, labeled as text-files 1 to 8 : two of them elicited by Kari'ña natives, two by Pemón ones, and four more by Ye'kwana ones; a total of 31 motifs were indexed within these eight text-files. The motifs identify human and non human entities with fantastic physical and behavioral traits. Furthermore, the MI includes motifs referring activities performed by the above-mentioned kind of entites, for which especial attitudes and instruments are required. In this article, each motif presented to the reader both in context and in a separate matrix in which every descriptor fits within the type(s) and subtype(s) set up by Thompson (op. cit.); Valory (1967) and Wilbert (1970, 1975). The analyzed tales were collected in the native languages by the author, and they were transcribed by him as part of his researches on Kari'ña, Pemón and Ye'kwana morphosyntax. Nonetheless, for this paper, the author used segments previously translated into Spanish by Civrieux (1970, 1976); Armellada and Bentivenga (1980); Guevara (2011); Armellada (1973); and Arreaza Adam (2005). The final MI supplied the data for an additional attempt to characterize ethnoculturally these northern Carib peoples.
\end{abstract}

KEYWORDS: Ethnolinguistics; Folk literature; Northern Carib languages.

RESUMEN: Este estudio está circunscrito al contexto de tres etnias de la familia caribe, sub-rama norte, específicamente kari'ña, pemón y ye'kwana, todas radicadas dentro de los confines territoriales de Venezuela; sobre estas en conjunto ---en un marco etnolingüístico--- se ha realizado la indización de los elementos léxicos identificatorios de los 'motivos' (Motif-Index of Folk-Literature, Stith Thompson 1955-1958) contenidos en narraciones orales utilizadas por estos pueblos originarios para tramitir sus tradiciones de una a otra generación. Thompson (1946, pág. 415; 1950-1955, pág. 1137) define 'motivo' como "el elemento más pequeño de una narración que tiene el poder de persistir en la tradición". El índice de motivos, o IM, resultante deriva de 8 narraciones, etiquetadas archivos-texto 1 a 8: 2 de ellas correspondientes a los kari'ña, 2 a los pemón, y 4 a los ye'kwana. En los 8 archivos-texto se indizaron 31 motivos con referencia a entes humanos y no humanos, con rasgos físicos y comportamientos fantásticos, mayoritariamente imaginarios.También, se incluyeron motivos que aluden actividades realizadas por tales seres, para las cuales se requieren aptitudes e instrumentos de los que no disponen las gentes comunes. Los motivos indizados fueron presentados tanto contextualizados como en matrices separadas cuyos descriptores encajan dentro de tipos y subtipos definidos por Thompson (op. cit.); Valory (1967); y Wilbert $(1979,1975)$. Las narraciones utilizadas fueron recopiladas por el autor en kari'ña, 
pemón y ye'kwana, y trascritas por este como parte de sus investigaciones sobre la morfosintaxis de estas lenguas. Sin embargo, para este estudio en particular, el autor se apoyó en segmentos de las traducciones al español de dichas narraciones previamente publicadas por Civrieux (1970, 1976); Armellada y Bentivenga (1980); Guevara (2011); Armellada (1973) y Arreaza Adam (2005). El IM constituido ha proporcionado datos para una adicional primera aproximación a la caracterización etnocultural de estos pueblos caribes del norte.

PALABRas Clave: Etnolingüística; Literatura oral; Lenguas caribes del norte.

\section{Preliminares}

Este estudio hace accesible en español parte del acervo artístico oral de tres grupos étnicos caribes establecidos en regiones del territorio venezolano localizadas en ambas márgenes del río Orinoco. Ya antes el material referido había sido divulgado en español, e incluso en otros idiomas, sin embargo los motivos contenidos en las narraciones en kari'ña, pemón y ye'kwana ahora ofrecidas nunca antes se indizaron, es decir, se tipificaron en base a criterios preestablecidos que sistematizarían los estudios sobre el tema, y permitirían la adición uniforme de nuevos motivos en la medida en que se ampliaran los datos etnolingüísticos. Fue esta última la tarea que el autor desarrolló con el grupo de narraciones recolectadas durante sucesivas sesiones de trabajo de campo que en principio le habían servido para respaldar algunas de sus descripciones tipológicas de aspectos gramaticales de las referidas lenguas. En particular, en esas narraciones fueron seleccionados los términos referentes a actores o personajes, y eventos e instrumentos que representaban "motivos" (Thompson 1977 [1946]) dentro de las cosmovisiones de estas tres etnias originarias. Thompson (1977 [1946]) en The Folktale define "motif" como "[...] the smallest element in a tale having a power to persist in tradition. In order to have this power it must have something unusual and striking about it" (pág. 415). Mas tarde, en Motif-Index of Folk-literature (1955-1958), Thompson suministra una definición mas "cautelosa", la cual expresa en los siguientes términos: "[...] anything that goes to make up a traditional narrative..." (pág. 1137). Thompson advierte que "When the term motif is employed, it is always in a very loose sense, and is made to include any of the elements of narrative structure" (pág. 1137). En esta oportunidad, para la selección, tipificación y caracterización de estos motivos se mantuvieron las variedades introducidas por Thompson en Motif-Index of Folk-literature (1955-1958), así como aquellas agregadas por Wilbert con referencia a grupos aborígenes suramericanos luego de sus estudios referentes a los warao (1970) del delta del Orinoco y los selknam de la Patagonia (1975). El procesamiento unificado de estos materiales no solo enriquecería el conocimiento existentes al respecto, sino que aumentaría las posibilidades de comparar las tradiciones de los pueblos originarios de distintas regiones de nuestro subcontinente.

Como ha sido anticipado, la faceta literaria de este estudio estuvo cercanamente ligada al planteamiento central de un proyecto lingüístico cuya meta en el mediano y largo plazos era recolectar datos que tras análisis condujeran a precisar las lenguas que pudieran encontrarse integradas en la sub-rama norte de la familia caribe, así como delimitar geográficamente sus territorios. La recopilación de datos lingüísticos y culturales para tales cometidos ya había sido iniciada por el autor a mediados de los años 1990, primeramente trabajando con los kari'ña y más tarde con los pemón y los ye'kwana. Las narraciones de valor etnocultural contadas por nativos en sus lenguas, luego de ser transcritas y glosadas en español por el autor, fueron aproximadas a las versiones en esta última lengua ofrecidas 
por Civrieux (1970, 1976); Armellada y Bentivenga (1980); Guevara (2011); Armellada (1973) y Arreaza Adam (2005), quienes ya antes las habían recopilado en el marco de investigaciones relacionadas con los sistemas de creencias de dichas etnias.

Debe ser destacado que esta indización operó exclusivamente sobre términos ajustados a la noción de motivos (Thompson 1977 [1946]) que fueron proferidos por los nativos en sus lenguas durante sus encuentros con el autor. La tipificación y sub-tipificación de estos motivos, y los descriptores elaborados para cada uno de ellos, surgieron de consideraciones pragmáticas, sintácticas y semánticas con origen en los dos discursos ---aquel en la lengua nativa y en la española--- en la medida en que ambos mostraban suficiente superposición, independientemente de las peculiaridades gramaticales y/o estilísticas que puedan reconocerse en las traducciones de Civrieux (1970, 1976); Armellada y Bentivenga (1980); Guevara (2011); Armellada (1973) y Arreaza Adam (2005). ${ }^{1}$ Es también relevante señalar que en gran medida fue adoptada la terminología introducida por Thompson [MotifIndex of Folk-Literature (1955-1958)], aunque se acogieron los ajustes introducidos por Wilbert $(1970,1975)$ en atención a peculiaridades de los aborígenes suramericanos. Con la sincronización de estos rasgos tipológicos se estaría allanando el camino de quienes más adelante se interesaran en profundizar sobre este tema y sus derivaciones.

Los tres grupos étnicos de interés investigativo tienen una notable representatividad demográfica dentro de los plueblos originarios de Venezuela, un conjunto que agrupa un total de 724.592 individuos (INE-Venezuela, Censo 2011). De esa población, más de la mitad pertenece a la etnia wayuu/guajiro (413.437 sujetos, 57.1\%); en el restante cuentan los otros 32 grupos étnicos (311.155 nativos, $42.9 \%$ ). En el cuarto superior de la tabla de distribución numérica y porcentual de los grupos indígenas del Censo 2011 los kari'ña constituyen el 4.7\%, los pemón el 4.2\% y los ye'kwana el 1.1\% (INE-Venezuela, Censo 2011). Los kari'ña ocupan extensas llanuras desde el cento del estado Anzoátegui hasta orillas del río Orinoco en el sur; también habitan en comunidades riverinas en las planicies del este del vecino estado Monagas, en la región nororiental del país, una zona de intensa explotación petrolera. La razón del alto riesgo en que se encuentra la cultura y la lengua kari'ña guarda relación con la elevada presencia 'criolla' en esos territorios y con el predominante manejo del español en todas las rutinas cotidianas. El Censo 2011 reporta 33.824 kari'ñas, de los cuales más de la mitad se han incorporado a la vida urbana en las ciudades y pueblos de la región, y ya se han alejado definitivamente de la vida en sus asentamientos rurales; los cerca de 15.000 que viven en poblados originarios como Cachama, Tascabaña, Caico Seco, etc., en un 70\% solo hablan español, y $92 \%$ de los bilingües utiliza esta lengua extranjera para su comunicación diaria.

Por otra parte, las tierras ancestrales de los pemón se sitúan en la alta meseta selvática de la Guayana venezolana conocida como La Gran Sabana, en el sureste del

${ }^{1}$ En general, con respecto a la compilación de las narraciones tradicionales de los pueblos aborígenes del continente americano, es importante tener en cuenta que constituye un proceso de alta complejidad por implicar transcripciones en las propias lenguas autóctonas ---a menudo poseedoras de estructuras sintácticas totalmente distintas de aquellas de las lenguas indo-europeas--- así como interpretaciones que suelen encontrarse interferidas por los sistemas de creencias de los recopiladores, especialmente si son misioneros. A pesar de que en el caso de las narraciones kari'ña, pemón y ye'kwana hayan podido observarse algunas divergencias sintácticas, las cosmovisiones de los correspondientes grupos étnicos nunca resultaron afectadas, conservándose así valores originales como fuentes etnográficas y artísticas. 
estado Bolívar, limítrofe con Brasil y Guyana. Son 30.148 individuos, de los cuales cerca de 28.000 hablan su lengua nativa (INE-Venezuela, Censo 2011). A pesar de que casi el $50 \%$ de los pemón son bilingües pemón-español, la estabilidad de la lengua se mantiene porque más de 10.000 nativos son exclusivamente monolingües. En relación a la población ye'kwana, el Censo 2011 reporta 7.997 personas, de las cuales apenas 200 no hablan su lengua nativa. Evidentemente contribuye con la gran vitalidad de esta lengua el hecho de que el grupo se encuentra disperso por un vasto territorio selvático en el ángulo noreste del estado Amazonas, en los alrededores del delta del río Ventuari, afluente del Orinoco. El territorio ye'kwana se extiende hacia el este hasta las márgenes de los ríos Caura y Erebato en el estado Bolívar. Dado que Puerto Ayacucho, la capital del estado Amazonas, es un enclave inmediato a muchas comunidades ye'kwana los miembros de esta etnia se muestran económicamente activos, y desarrollan actividades cooperativas para el cultivo del cacao y la comercialización de la miel de abejas. Esto ha masificado el bilingüismo ye'kwana-español, aunque como antes señalado un gran número de sujetos se mantiene monolingüe, particularmente aquellos que habitan en las zonas mas remotas, aledañas a la serranía de Maigualida, región fronteriza con Brasil.

\section{El planteamiento investigativo y sus fundamentos teóricos}

El proyecto estuvo circunscrito al ámbito de tres etnias caribe, sub-rama norte, hablantes respectivamente de kari'ña, pemón y ye'kwana, todas ubicadas dentro de los confines territoriales de Venezuela. Los datos en kari'ña fueron recolectados por el autor en Tascabaña, una comunidad indígena establecida en las sabanas de la margen norte del río Orinoco en el estado Anzoátegui en el oriente del país. El material en pemón fue recolectado en Kavanayen, poblado de la Gran Sabana, al sur del río Orinoco, en el estado Bolívar, y el correspondiente al ye'kwana en Puerto Ayacucho, capital del estado Amazonas.

En el plan de investigación del proyecto se propuso el abordaje de fenomenología asociada con los contextos (i) lingüístico: estudios sobre unión clausal, ergatividad, deixis y anáfora, y comparativos, y (ii) literario: un glosario de términos de valor etnocultural en el marco de tradiciones transmitidas en forma oral. Varias de las investigaciones lingüísticas realizadas, producto de datos propios del autor recolectados en sucesivas sesiones de campo, han sido publicadas (ver Romero-Figueroa 2011; Romero-Figueroa 2013abc; Romero-Figueroa 2015). En paralelo, la vertiente literaria del proyecto progresó en su fase de revisión documental, en la que se incluyó la selección y transcripción de narraciones tradicionales de los kari'ña, pemón y ye'kwana. En este último renglón se centró la atención en aquellos motivos representados por caracteres humanos y no humanos, con rasgos físicos y comportamientos fantásticos, mayoritariamente imaginarios. También, en esas narraciones se tuvo en cuenta los motivos que hacían referencia a actividades realizadas por tales personajes mitológicos, para las cuales requerían habilidades físicas e instrumentos de los que no disponen los seres comunes. Todos estos héroes, y a veces también algunos antihéroes, lejos de representar recuerdos de un pasado ya distante, se mostraban vívidos en las mentes de los narradores nativos, e indudablmente resultaban piezas de las cosmovisiones de los tres grupos étnicos escrutados. En los datos recolectados, 
por ejemplo, se percibieron como personajes prominentes dentro del sistema de creencias de los kari'ña dos hermanos gemelos, que en los casos de las tradiciones de los pemón y ye'kwana constituyen una dupla en la cual un hermano es mayor que el otro. En todas las tres etnias precitadas, en los entornos de estos hermanos se repiten tres situaciones: (1) el padre está ausente y su figura es siempre recordada por la madre, (2) la madre es prontamente excluida de las vidas de los hermanos, en todos los casos de forma violenta o por medio de engaños, y (3) los hermanos realizan viajes en donde hacen descubrimientos o invenciones que beneficiarán las generaciones posteriores. En particular, en las narraciones pemón y ye'kwana los hermanos son mostrados como sujetos fisgones; y por esta razón suelen ser estas muy extensas, ya que por curiosos los hermanos protagonizan episodios incidentales enfocados en travesuras y artimañas para vencer a aquellos que en posesión de habilidades mágicas, como por ejemplo, la de transformar su apariencia, intentarán aniquilarlos. Estas narraciones ejemplifican la visión humana principista que impone el bien sobre el mal, o al débil sobre el fuerte. En el marco de las narraciones sobre los dos hermanos, gemelos o no, es recurrente la figura de la vieja sapo, a veces referida como rana. Este personaje puede ser un sapo con apariencia humana, o un ser humano verdadero que se convierte en sapo, e incluso en otra criatura con hábitos tanto humanos como de batracio. La anciana sapo juega un importante rol en el proceso de supresión y subsiguiente exclusión de la madre de los hermanos, a quien la primera siempre pretende reemplazar dentro del entorno familiar. Por otra parte, es frecuente la vinculación de la vieja sapo al descubrimiento del fuego ya que ella suele ser la única propietaria del mismo. Ella es custodia del fuego, y suele ocultarlo de los demás. Los hermanos son los responsables de hallarlo y ponerlo al alcance de todos los seres humanos, quienes a partir de ese momento empiezan a hacer uso del mismo en sus actividades cotidianas. Además de la anciana sapo, otros animales míticos mágicos son los pájaros; todas las narraciones coinciden en señalar que desde los primeros tiempos ayudaron a los hombres en la agricultura. En todos los casos, son las aves quienes instruyen a los hombres como cultivar e incluso llegan a proporcionarles las semillas para iniciar las siembras. Las aves también contribuyen notoriamente con los humanos en el descubrimiento de virtudes y peligros de las plantas, y suministran orientaciones pertinentes en las tareas de cacería.

Así mismo, fueron motivos de interés en este estudio los mencionados en las narraciones cosmogénicas de los ka'riña, pemón y ye’kwana, caracterizados por ser protagonizadas por seres que provienen del espacio exterior, aludidos como hijos del sol, o "la luz", o "la luz inmensa" (Guevara 2011). Significativamente, ninguno de ellos descienden de madres en el sentido terrenal; contrariamente se dan casos en que son estas productos de los hijos, como en el caso de Wanadi 'sol sin atardecer' (Arreaza-Adam 2005), y por extensión el sol entre los ye'kwana, quien crea a su imagen y semejanza a los emisarios que han de venir a la tierra a fabricar los pobladores; uno de estos hijos de Wanadi con su magia hace su propia madre. Personajes, objetos, poderes mágicos, transformaciones, etc., como los precedentemente destacados evidentemente dan forma y moldean las visiones de mundo de los kari’ña, pemón y ye'kwana.

Todos los motivos aludidos en este estudio fueron indizados conforme a parámetros incluidos en Motif-Index of Folk-literature (1955-1958) de Stith Thompson, resumidos en el ANEXO 1. El Motif-Index es un instrumento concebido para facilitar las investigaciones etnolingüísticas comparativas puesto que a grandes rasgos agrupa de manera sistemática 
los motivos posibles en los cuentos populares, leyendas, mitos y baladas de todo el mundo. El catálogo de motivos de Thompson correlaciona personajes y actuaciones de estos, así como sus instrumentos y aplicaciones, con marcadores espacio-temporales; esta multifactorialidad posibilita la generación de una amplia gama de significados e interpretaciones. Por ejemplo, un ser mítico de la génesis puede estar representado en un hombre cuya actuación trae beneficios a su sociedad por lo que puede ser visto por esta como un héroe. Contrariamente, algún otro ser terrenal humano del mismo período de la creación valiéndose de dotes especiales puede transformarse en un ente no humano para ejecutar acciones adversas al orden natural de las cosas, y en consecuencia es entonces percibido como un malefactor.

La amplia perspectiva utilizada por Thompson para analizar los motivos en la cuentística popular concede a Motif-Index of Folk-Literature, divulgado en seis volúmenes escritos a lo largo de cinco años, el rango de obra clave para los estudios sobre la folclorística. A partir de entonces, esta última se incorporó al curriculum universitario, obteniendo una notoriedad que autores posteriores como Alan Dundes ${ }^{2}$ y Jan Harold Brunvand $^{3}$ contribuyeron a mantener. El trabajo de Thompson perfecciona el iniciado por Antti Aarne ${ }^{4}$ con quien realmente se marca la distinción entre el abordaje académico de la narrativa folclórica y la práctica de aficionados e inexpertos. Fue de esta manera como se tornó sine qua non para los investigadores en numerosas universidades del mundo la identificación de las narraciones folclóricas a través de motivos y tipos de textos o cuentos.

La literatura corriente muestra que ha habido considerable discusión de los conceptos "motivo" y "tipo de cuento". Thompson (1946, p. 415; 1950, p. 1137) concibió "motivo" como "el elemento más pequeño de un cuento que tiene el poder de persistir en la tradición". Quizás la más lúcida delineación del concepto "tipo de cuento" fue ofrecida por el húngaro János Honti (1937) en su ensayo A Mese világa. Honti propuso tres diferentes formas de considerar un tipo de cuento como una unidad de análisis viable: (i) debe exhibir un encadenamiento de motivos, (ii) debe presentarse como una pieza valiosa y particular, y (iii) debe ser percibido como una pieza única que podría manifestarse con variantes o versiones diferentes.

\section{Metodología}

Los motivos indizados se encuentran contenidos en las narraciones en kari'ña, pemón y ye'kwana proferidas por informantes nativos durante sesiones de trabajo de campo conducidas por el autor a partir de 1995. A pesar de que las narraciones fueron transcritas en las lenguas correspondientes y glosadas en español durante la fase de desarrollo de algunas

${ }^{2}$ Alan Dundes (1934-2005) fue un folclorista, profesor de la Universidad de California, Berkeley. Su labor fue capital en el establecimiento de los estudios de folclore como materia académica. Escribió trece libros, académicos y populares al mismo tiempo, y editó o coeditó dieciocho más.

3 Jan Harold Brunvand (1933-) es un profesor de la Universidad de Utah, en Estados Unidos. Se le conoce sobre todo por sus trabajos sobre leyendas urbanas y folclore moderno, conceptos que ha contribuido decisivamente a extender y divulgar.

4 Antti Aarne (1867-1925) fue un folclorista finés, más conocido por desarrollar un sistema de clasificación de fábulas clásicas conocido como Aarne-Thompson, llamado así a partir de la traducción al inglés y posterior ampliación por parte del folclorista estadounidense Stith Thompson. 
de sus descripciones morfosintácticas, los textos en español que han sido incorporados al estudio (ver Sección 4) son las versiones ofrecidas por antropólogos y misioneros que en diferentes épocas y lugares, convivieron con los kari'ña, pemón y ye'kwana como resultado de tareas particulares desarrolladas en comunidades establecidas en las regiones oriental y sur de Venezuela, cercanas todas a ríos tributarios del Orinoco. La prolongada convivencia de estos con los indígenas les permitió profundizar en el conocimiento de sus tradiciones, y los legitimó como traductores de sus leyendas y cuentos. Las traducciones pertenecen a Civrieux (1970, 1976); Armellada y Bentivenga (1980); Guevara (2011); Armellada (1973) y Arreaza Adam (2005).

En la Sección 4 de este estudio, cada término que representa un motivo fue mostrado tanto en forma contextualizada, es decir, inserto en el cuerpo de la narración, como aisladamente en una matriz que incluye parámetros establecidos por Thompson. En cada matriz individual se señala: (i) Tipo y subtipo de motivo. En este renglón se aplican rigurosamente los criterios de Thompson para agrupar e reconocer los motivos por tipos/ subtipos [o tópicos/subtópicos, según otros expertos en narrativa tradicional como Valory (1967), y Wilbert (1970, 1975)] (ver ANEXO 1). Así mismo, en este estudio se mantiene la misma nomenclatura identificatoria de los tipos y subtipos presentados en el ANEXO 1. (ii) Número de identificación del motivo. Este es un código numérico que en secuencia correlativa identifica cada motivo en su primera aparición; (iii) Motivo (personaje, acción, escenario o lugar, y objeto o instrumento nombrado en la narración). Se aplican nuevamente los criterios de subdivisión de los tipos de Thompson y se especifican los sub-tipos existentes en kari'ña, pemón y ye'kwana (ver ANEXO 1). El motivo es siempre expresado en la lengua nativa; y (iv) Descriptor, el cual contiene una breve explicación de lo que significa o refiere el motivo.

\section{El indice de motivos (IM) kari'ña, pemón y ye'kwana}

Una vez concretada la selección de narraciones de cada etnia a partir de las fuentes primarias, las piezas escogidas fueron transferidas al IM acogiendo el ordenamiento hecho por Civrieux (1970, 1976); Armellada y Bentivenga (1980); Guevara (2011); Armellada (1973) y Arreaza Adam (2005). Estos autores generalmente presentaron la información desplazándola desde los eventos del génesis, protagonizados por entes superiores cosmogónicos, hasta llegar a los detalles de las acciones realizadas por humanos que se tornaron en héroes culturales como resultado de sus participaciones en las luchas entre el bien y el mal. Estas confrontaciones en todos los casos fueron tratadas desde la perspectiva de sus efectos en el ordenamiento de la vida de todos los hombres. Los títulos por los autores asignados a dichas piezas fueron respetados con rigurosidad.

En el IM, cada título de un texto representa un archivo enumerado correlativamente dentro de su correspondiente sección: la SECCIón A agrupa las piezas textuales de los kari'ña, la SECCIón B las de los pemón, y la SECCIón C las de los ye'kwana. Los números de identificación de los archivos-textos no se repiten y van de manera creciente desde (1) hasta (31): la SECCIón A: kari'ña contiene los ARCHIVOS-TEXTO 1 y 2, la SECCIón B: pemón contiene los ARChivos-TeXTo 3 y 4; y la SECCión C: ye'kwana contiene los ARChivos-TEXTO 5, 6, 7 y 8. En cada sección y en cada archivo-texto también se 
enumeraron correlativamente los 31 motivos indizados: la SECCIÖN A: kari' ña cuenta con 6 motivos; en la SECCIón B: pemón aparecen 10 motivos; y en la SECCIón C: ye'kwana se agrupan 15 motivos. La identificación numérica de cada motivo se colocó entre paréntesis a la izquierda del mismo solamente en su primera aparición en el cuerpo del correspondiente archivo-texto. Con la finalidad de facilitar la visualización de cada motivo en el archivotexto, este es resaltado en negritas.

En este punto de la exposición acerca de la matriz básica del IM utilizada en el estudio es relevante señalar que los motivos contextualizados en los archivos-texto permiten al lector valorar culturalmente los descriptores. Además, para facilitar la comprensión de las relaciones entre los motivos, y sus descriptores y tipos y subtipos, estos han sido listados en el ANEXo 2.

A continuación se ofrecen los archivos-textos y las matrices individuales correspondientes a los motivos indizados:

\section{SECCIÓN A: KARI’̃̃a}

ARCHIVo-TeXto 1: En la casa de (1) Akodumo (Civrieux 1976)

Un indio borracho, después de una fiesta, se bañó en una laguna y se encontró con (2) Amanna, bonita mujer de la nación que le pidió seguirla en el agua. Al principio él no quiso y después se dejó convencer. Dentro del agua vio las casas llenas de gentes y muchas mujeres jóvenes que le obsequiaron bebidas. Amanna le presentó a su padre y se quedó el hombre con los (3) akodumño. La madre del hombre lo buscó hasta la orilla del agua, no halló rastros, creyó que se había ahogado y tomó luto. Más tarde, el hombre sintió deseos de volver a verla, y fue a visitarla. La madre le preguntó dónde había estado y él contestó "por allí, caminando", y no hizo caso a sus súplicas para que se quedase, sino que volvió a la casa de los akudumño por mucho más tiempo. Luego volvió otra vez a casa de su madre. Uno de sus hermanos le preguntó dónde había estado. Se enfureció y le dijo ¿Por qué preguntas? Y volvió al agua. Volvió, mucho tiempo después a la casa de la madre con su mujer Amanna. Su hermano estaba borracho y le preguntó: --- ¿Estuviste con los akudumño?” --- “iSíl”, contestó el hombre embravecido, --- "Y esta es uno de ellos, mi mujer". Amanna se ocultó enseguida zambulléndose en el agua. El hombre la siguió pero, en la orilla del agua, llegaron los akodumño y lo mataron porque había revelado su secreto.

\begin{tabular}{|l|}
\hline TIPO(S): [A] LOS ORÍGENES: SERES Y SUCESOS. \\
\hline$N^{\circ}(1)$, ARCHIVO-TEXTO 1 \\
\hline Motivo: Akodumo [ ako'dũmo ] \\
\hline $\begin{array}{l}\text { SUB-TIPO(S): [A.b.b1] Primeros entes terrenales (entes custodios del cielo, el agua, la } \\
\text { tierra y/o el fuego). }\end{array}$ \\
\hline
\end{tabular}

${ }^{5}$ El universo kari'ña plantea 4 regiones con sus respectivos dueños: kapuano, dueño del firmamento y abuelo de los abuelos; maware, dueño del cerro; akodumo, dueño del agua, e Ioroka, dueño de la tierra (Guevara 2011, pág. 240). 
Descriptor: Espíritu dueño del agua ${ }^{5}$---abuelo de las serpientes--- que domina sobre todos los seres acuáticos de este mundo. Tiene familiaridad con los pájaros acuáticos, los cuales dependen a la vez del agua y del cielo, por esa razón Akodumo es mágicamente poderoso y sirve de auxiliar a los akodumo, sus mensajeros y sirvientes, encargados de custodiar las aguas.

TIPO(S): [A] LOS ORÍGENES: SERES Y SUCESOS.

$\mathrm{N}^{\circ}(2)$, ARCHIVO-TEXTO 1

Motivo: Amanna [ã'mãn:a ]

SUB-TIPO(S): [A.b.b1] (ver ANEXO 1)

Descriptor: Ser de apariencia humana que vive bajo el agua. Es una mujer hermosa que atrae hombres escogidos para convertirlos en akodumo, o custodios de las aguas. Es instructora de fórmulas mágicas, y proveedora de talismanes y otros objetos que protegen contra diversos males. Su actividad ocurre en el mundo sub-acuatico, lugar secreto de ubicación desconocida para los hombres ordinarios.

TIPO(S): [A] LOS ORÍGENES: SERES Y SUCESOS.

$\mathrm{N}^{\circ}(3)$, ARCHIVO-TEXTO 1

Motivo: akodumño [ aks'ðũmpo ]

SUB-TIPO(S): [A.b.b1] (ver ANEXO 1); [A.b.b2] Primeros entes terrenales (entes que se transforman mágicamente).

Descriptor: Grupo de seres míticos, con apariencia humana, que viven en lugares ubicados en los fondos de ríos y lagunas. Dominan sobre todos los pájaros, mamíferos, reptiles, batracios y peces que viven en el agua y sus orillas. Son mensajeros y sirvientes de Akodumo. Tienen forma humana en lo invisible y forma de gigantescas culebras de agua, o anacondas (eunectes murinus), cuando aparecen a la vista de los hombres ordinarios. Sus poderes mágicos deben legarlos a hombres y mujeres comunes escogidos. Los akodumo atraen a la gente hasta su nación, de la cual pueden retornar si desean siempre y cuando guarden el secreto de su existencia.

ARCHIVO-TEXTO 2: Los gemelos y la come gente (El origen de los frutos) (Armellada y Bentivenga 1980) ${ }^{6}$

Cuando empezaron los tiempos, (4) Bedu, el sol, estaba muy enamorado de una mujer kari'ña y una vez se la llevó a parajes celestes para amarla. Los nubarrones y las trombas de agua sirvieron de lecho a sus jugueteos y a sus copulaciones entre las estrellas, hasta que llegó el día de la separación. --- "A mi casa debo irme" ---, le dijo Bedu a su amor. --- “YY donde está?" ---, le preguntó ella. Él le contestó:: --- "Por ahí, al llegar al cruce de caminos de las dos plumas, la roja de guacamaya te llevará a mi morada, y la otra de paují negro, a un sendero donde viven los (5) tarümño. Ese no lo debes andar nunca" --- le dijo, perdiéndose en el follaje de sus propios llamarones. Ella había quedado preñada y llevaba gemelos en su vientre, quienes serían los primeros dos (6) puidei del mundo. Llegado

\footnotetext{
${ }^{6}$ Sobre algunos segmentos de esta narración se han superpuesto términos y expresiones de una versión presentada por Ferro (2014).
} 
el día, la mujer salió a parir sus gemelos en la casa de Bedu. Los gemelos eran muy habladores e inquietos. La molestaban sobremanera. Durante el camino no hacían más que decir: "Mira, mamá, esas flores bonitas". "Contempla, mamá, esos frutos maduros". En una de esas la mujer se cayó, y disgustada por ese atrevimiento de sus hijos, les pegó por sobre la barriga, luego de regañarlos. Todavía no estaban afuera y ya la fastidiaban.

Cuando llegó a la encrucijada, la mujer no recordaba las señas convenidas con Bedu. Muy asustada las preguntó a los gemelos, pero estos, enojados, no le contestaron. Tomó la mujer el camino equivocado y arribó al caney de una anciana. Esta cocinaba en ese momento. La mujer cansada y hambrienta le pidió alojamiento por esa noche. La anciana le ofreció comida, agua, un cuarto y le ayudó a acostarse. En la noche, la anciana mató a la mujer y se la comió después de extraerle los gemelos. Desde ese día los recién nacidos tuvieron por madre a la anciana. En unos días ya habían crecido y convertido en jóvenes pues por ellos corría sangre de astros. Los dos jóvenes resultaron hábiles y afamados cazadores. Todas las noches traían paujíes, lapas y rabipelados que la anciana cocinaba y comía sin darle a ellos. La anciana sólo les servía unas tortas blancas con sabor a casabe. Los jóvenes gemelos cansados de la misma comida, se preguntaron de donde sacaba la anciana el casabe si ella no sembraba yuca. Entonces se pusieron de acuerdo para observar como hacía. De un enorme sapo la anciana extraía una leche espesa que echaba sobre el budare, y de allí salían las sipipa. ${ }^{7}$ Después se ponía a conversar con el animal: --- "Ya llegará el día en que no te sacaré más leche para ellos. De un momento a otro me los comeré" ---. Al darse cuenta de que la anciana no era su mamá sino un tamurü, decidieron matarla. Esa noche, al regreso de una cacería de paujíes, la oyeron decir a otros dos tarümño --- "Quien nos está cazando son los hijos del sol" ---, y les contó como llegaron hasta ella.

Al atardecer del siguiente día, los gemelos le dijeron a la anciana que pensaban hacer una roza para sembrar, pero para tener una buena cosecha era necesario que ella hiciera sus cantos encima de una troja que ellos levantarían. A los dos días estuvo la roza y se montó la troja en el tercero. Cuando la anciana comenzó a cantar, los dos gemelos prendieron candela a un poco de leña que estaba debajo. La anciana no tuvo tiempo de saltar, y el fuego la quemó como una rama seca, y fue allí donde los kari'ña fundaron la primera sementera y donde se dieron por primera vez todos los frutos: ocumo, mapuey, ñame, y muchos más.

TIPO(S): [A] LOS ORÍGENES: SERES Y SUCESOS.

$\mathrm{N}^{\circ}(4)$, ARCHIVO-TEXTO 2

Motivo: Bedu [ $\left.\mathbf{\beta} \varepsilon^{\prime} \mathbf{\partial u}\right]$

SUB-TIPO(S): [A.a] Creadores [entidades superiores cosmogónicas/cósmicas/celestes (el padre sol, los hijos del sol y la luna, las constelaciones, etc.)].

Descriptor: "Luz inmensa" entre los kari'ña (Guevara 2011). El iniciador de la vida de los hombres, quienes bajaron desde los dominios de su hacedor por un camino señalado por este hasta llegar a sus actuales tierras.

${ }^{7}$ Tortas de almidón de yuca. 
TIPO(S): [A] LOS ORÍGENES: SERES Y SUCESOS.

$\mathrm{N}^{\circ}$ (5), ARCHIVO-TEXTO 2

Motivo: tamurümño [tãmu'rũnumjo] tarümño [ tã' cũnumno ] tamurü [ tãmu'ru]

SUB-TIPO(S): [A.c] Entes malevolentes (la presencia de las fuerzas negativas, la lucha entre el bien y el mal, y entre el débil y el fuerte).

Descriptor: Mensajeros y sirvientes de Mawari (o Maware), el espíritu dueño del cerro, los farallones y las cavernas. Son entes perjudiciales, rivales de aquellos otros benefactores y protectores. Los tamurümño son dueños de la vida y de la muerte, “... son hombres y mujeres poderosos y ambivalentes, amorales" (Guevara 2011, pág. 243) que pueden causar la muerte a las personas después de robarles las almas. Inicialmente seducen a sus víctimas con acciones que las favorecen, inclusive curarles heridas y sanarlos si están enfermos, y luego de hacerlas parte de sus entornos, las desaparecen para siempre. Por ser antropófagos, los restos nunca son encontrados. Los tamurü son una variedad negativa de piai, termino general que designa a todos los practicantes de la shamanería.

TIPO(S): [A] LOS ORÍGENES: SERES Y SUCESOS.

$\mathrm{N}^{\circ}(6)$, ARCHIVO-TEXTO 2

Motivo: puidei [ pwi'ðย] ]

SUB-TIPO(S): [A.b.b4] Primeros entes terrenales (descendientes de las relaciones entre astros y animales con seres humanos); [A.e] Ordenamiento de la vida humana [el uso general del fuego, el inicio del arte de la cacería con curare (strychnos guanensis), el inicio de la cacería grupal organizada, el inicio de la actividad agrícola, el inicio de la práctica shamanística, el inicio del rito funerario, el inicio de las desviaciones de la conducta humana, etc.].

Descriptor: Seres benefactores de la vida cotidiana y sanadores de enfermos. Son considerados los shamanes antecesores de los actuales, mensajeros de Maware --. el espíritu dueño del cerro. Por correr por sus venas sangre de astros, estos dos puidei primigenios se encontraban dotados de grandes poderes, por lo que encabezan una especie de aristocracia conformada en base a la condición de poseer "almas celestes" (Guevara 2011, pág. 248), aquellas de hombres y mujeres con el privilegio de vivir en el cielo y en la tierra. Las acciones de los dos puidei primigenios trajeron a los kari'ña la primera sementera donde se dieron por primera vez todos los frutos.

\section{SECCIÓN B: PEMÓN}

ARCHIVO-TEXTo 3: Leyenda de Mochima y Maruk (Armellada 1973)

"Mira, aquí tienes el corazón de la danta, mi yerno". Así lo dijo el suegro, un mensajero del espíritu dueño del cerro, y los farallones y las cuevas. Y el yerno lo cogió y lo puso en un cuenco de roca, y lo guardó. El corazón de la danta se transformó en un pájaro que fue creciendo poco a poco hasta llegar a emplumarse. Este fue (7) Mochima.

Cuando se hizo grande, Mochima se comió a mucha gente. Por eso los hombres buscaron con qué matarlo. Reuniéndose en gran número, consultaron entre sí, pero faltó por consultar a (8) Maruk. Le dijeron al Maruk: --- "Después de haber conferenciado todos, 
resulta que a ti no te hemos preguntado. ¿No será acaso que tú hayas visto una cosa más?" ---"Pues, sí; allá lejos hay una cosa, no sé qué, muy adormecedora. La carne de la gallineta de monte es amarga porque fue quien encontró y probó la mata de curare (Strychnos guianensis)". --- "Siendo así, iré a probar el árbol aquel", dijo un pájaro conocido como (9) ayiten. --- "Cuando lo pruebe y caiga, escuchareis como cuando la tierra tiembla", así dijo el ayiten. Y he aquí que se fue a probar el árbol. Y estando probándolo, el ayiten se cayó. ¡Pueu, tin!, y la tierra tembló. --- "Se cayó”, dijeron los hombres, y se fueron a verlo. Y lo encontraron, y vieron que los comejenes lo habían arropado con hojas de tabaco; y el ayiten se levantó. Por segunda vez el ayiten subió a probarlo, y por segunda vez cayó. --- “Este es?”, dijeron los hombres. Y reunidos muchísimos de ellos cortaron el árbol y lo compusieron para curare.

Teniendo ya el curare, ellos se fueron a flechar a Mochima. Pero como el corazón de Mochima era el cuenco de roca aquel, no le entraban las flechas. Y, aunque un (10) kurachi se lo estaba diciendo en su lengua, los hombres no lo entendían. --- "¡Chiró, chiró, chiró!", gritaba el kurachi. Quería decir: --- "Más allá, lanzando las flechitas por encima para que le caigan en la espalda". Por fin lo entendieron. Lo flecharon de aquella manera y Mochima se fue volando. Y ellos detrás flechándolo.

En su vuelo Mochimá los llevó hacia la (11) tierra de los madonkon. Por allá Mochima desfalleció. Allá, de sus plumas fue botando (12) patiri. Allá mismo lo taparon con la tierra de donde ahora salen las lombrices. Y allí brotó el (13) sanwoto que sirve para las cerbatanas. Por eso es que en la tierra de los madonkon existen las cerbatanas porque allí enterraron sus plumas. Parece que debiera haberlas en todas partes.

\begin{tabular}{|l|}
\hline TIPO(S): [A] LOS ORÍGENES: SERES Y SUCESOS. \\
\hline$N^{\circ}$ (7), ARCHIVO-TEXTO 3 \\
\hline Motivo: Mochima [ motfíma ] \\
\hline SUB-TIPO(S): [A.c]; [A.e] (ver ANEXO 1) \\
\hline Descriptor: Águila gigantesca y sanguinaria que comía seres humanos. Temida por \\
todos los hombres. Surgió del corazón de una danta que el suegro ---un mensajero del \\
espíritu dueño del cerro, había obsequiado a su yerno, el espíritu poseedor del rayo. \\
El regalo estuvo resguardado en un cuenco tallado en roca. El corazón de Mochima \\
quedó recubierto con la roca del recipiente que lo contenía; eso lo hizo un depredador \\
invulnerable. Despues de descubrirse sus flancos débiles, es cazado y con su muerte \\
sobrevienen acciones relacionadas con la fabricación de la cerbatana utilizada para cazar \\
con dardos envenenados con curare.
\end{tabular}

TIPO(S): [A] LOS ORÍGENES: SERES Y SUCESOS; [B] ANIMALES Y PLANTAS ESPECIALES.

$\mathrm{N}^{\circ}(8)$, ARCHIVO-TEXTO 3

Motivo: Maruk [ ma'ruk]

SUB-TIPO(S): [A.e] (ver ANEXO 1); [B.a] Animales amistosos que saben secretos. 
Descriptor: Es una gallineta de monte que conocía las propiedades tóxicas de la savia de la planta de curare porque le habían contado que uno de sus abuelos había comido sus hojas y flores. El sabor amargo de la carne de la gallineta de monte, según los pemón, es una consecuencia de haber probado el curare. Maruk guió a los hombres hacia la planta, la cual es una trepadora establecida es las copas de otros árboles, y que se confunde entre las frondas.

TIPO(S): [A] LOS ORÍGENES: SERES Y SUCESOS; [B] ANIMALES Y PLANTAS ESPECIALES.

$\mathrm{N}^{\circ}(9)$, ARCHIVO-TEXTO 3

Motivo: ayiten [ adzi't $\tilde{\varepsilon} \mathbf{n}]$

SUB-TIPO(S): [A.e]; [B.a] (ver ANEXO 1)

Descriptor: Es el más pequeño de los pájaros carpinteros. Al escuchar a Maruk, el ayiten fue a comprobar lo dicho por este, y tras ingerir varias veces el jugo de la planta de curare cayó en letargo. Los hombres lo revivieron y supieron por su intermedio cual era la planta que buscaban. La cortaron y prepararon flechas untadas con su savia para cazar a Mochimá.

TIPO(S): [A] LOS ORÍGENES: SERES Y SUCESOS; [B] ANIMALES Y PLANTAS ESPECIALES.

$\mathrm{N}^{\circ}(10)$, ARCHIVO-TEXTO 3

Motivo: kurachi [ kura'tgi ]

SUB-TIPO(S): [A.e]; [B.a] (ver ANEXO 1)

Descriptor: Es un ruiseñor de montaña, un pájaro común y abundante en la selva amazónica que posee un canto armonioso. Con sus repetidos trinos "chiró, chiró, chiró", advirtió a los cazadores que flecharan a Mochimá por la espalda, pues por el pecho las flechas no entrarían en su corazón por estar recubierto con roca. Comprendido el mensaje, lo persiguieron y lo flecharon varias veces hasta causarle la muerte en la tierra de los madonkon.

TIPO(S): [C] LUGARES ANCESTRALES Y SAGRADOS.

$\mathrm{N}^{\circ}$ (11), ARCHIVO-TEXTO 3

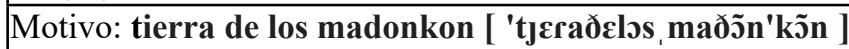

SUB-TIPO(S): [C.b] Referentes topográficos en la Tierra (montañas, cascadas, ríos, etc.). Descriptor: Madonkon es el término con que los pemón se refieren a los ye'kwana, grupo étnico de filiación caribe, sub-rama norte, que habita en una zona que se extiende desde el río Ventuari hasta el río Paragua, en la Guayana venezolana. Es una región selvática extensa adyacente al territorio pemón por su lado oeste. 
TIPO(S): [A] LOS ORÍGENES: SERES Y SUCESOS; [B] ANIMALES Y PLANTAS ESPECIALES.

$\mathrm{N}^{\circ}$ (12), ARCHIVO-TEXTO 3

Motivo: patiri [ pa'tiri ]

SUB-TIPO(S): [A.e]; [B.b] (ver ANEXO 1)

Descriptor: Lombrices de tierra muy grandes. Originariamente, estas provinieron de las plumas de Mochimá, una vez que este fue enterrado por los madonkon. Estas contribuyen con la fertilidad de las planicies anegadizas que bordean los ríos de las tierras bajas de la cuenca del Orinoco, y favorecen en ellas el desarrollo de plantas de bambú (arthrostylidium schomburgkii) y palmeras mabe o cola de pavo (iriartella setigera). De los tallos de estas plantas se obtienen los tubos para construir cerbatanas.

TIPO(S): [A] LOS ORÍGENES: SERES Y SUCESOS; [B] ANIMALES Y PLANTAS ESPECIALES.

$\mathrm{N}^{\circ}$ (13), ARCHIVO-TEXTO 3

Motivo: sanwoto [ sãnwo'to ]

SUB-TIPO(S): [A.e] (ver ANEXO 1); [B.d] Plantas y animales proveedores de recursos esenciales.

Descriptor: Cepas de bambú (Arthrostylidium schomburgkii) abundantes en la tierra de los madonkon, dada su fertilidad por la riqueza orgánica que patiri, o las lombrices de tierra gigantes, dan al suelo. De estas cepas se cortan las dos cañas para construir cerbatanas, instrumentos de cacería consistentes de una cubierta cilíndrica y de un cañón de menor diámetro, que permite con soplidos disparar a las presas dardos untados con curare. Un tipo similar de cerbatana consiste de un tubo externo labrado de un tallo de palmera mabe (Iriartella setigera) y de un cañón del bambú antes citado.

ARCHIVO-TEXTo 4: Erikawa y Ayu (Armellada 1973)

El árbol (14) erikawa era suegro del árbol (15) ayu. El erikawá le hizo los remedios a su yerno para que fuera un valiente cazador. --- "Ahora que te hice los remedios, no te pongas a conversar con las mujeres ni a enamorarte de ellas", le dijo el suegro a su yerno. Llegaron las mujeres y se pusieron a coquetearle al ayu. Unas de ellas le dijeron: --- "Vamos a bailar". Y él se fue a bailar con ellas. Y he aquí que mientras el ayu estaba bailando, lo vio su suegro. --- “CCaramba!”, le dijo el erikawá, "Si yo te dije que no hicieras eso". Por estas palabras el ayu se disgustó con su suegro el erikawa. Entonces el erikawá maldijo a su yerno el ayu diciendole: "Ya que así eres tú, desobediente a los consejos, se bravo de verdad y ve a tocarle las puertas a los (16) mawariton". Desde entonces los escogidos de Mawari para hacerlos shamanes aprecian mucho el árbol ayu, creen en sus propiedades sanadoras y protectoras, y no sin motivo, sino por lo que dice el cuento. Los viejos siempre decimos a los jóvenes: ---"No os hagáis remedios con el erikawá, sino con el ayu. Eso me enseñó mi suegro cuando fui a su casa. 
ROMERO-FIGUEROA - MOTIVOS CONTENIDOS EN NARRACIONES...

TIPO(S): [A] LOS ORÍGENES: SERES Y SUCESOS; [B] ANIMALES Y PLANTAS ESPECIALES.

$\mathrm{N}^{\circ}$ (14), ARCHIVO-TEXTO 4

Motivo: erikawa [ Erika'wa ]

SUB-TIPO(S): [A.e]; [B.d] (ver ANEXO 1)

Descriptor: "Especie de árbol cuyas hojas usan los piasan para sus tisanas" (Armellada y Gutiérrez 1981, pág. 61). Los piasan o shamanes son iniciados por los piaimá, seres fabulosos que viven en los bosques, y son mensajeros y sirvientes de Mawari ---el señor y dueño del cerro. Los piaimá, custodios de las montañas, son gigantes antropófagos que se transforman a voluntad. La enseñanza impartida por los piaimá a los piasan "es larga a base de ayunos, ingurgitaciones de alucinógenos y grandes vomitaderas inducidas por el humo del tabaco y por los cocimientos de hojas de erikawa (Armellada y Gutiérrez 1981). El erikawa primigenio poseía el don del habla, así como conocimientos sobre las propiedades alucinógenas y eméticas de sus hojas cocidas.

TIPO(S): [A] LOS ORÍGENES: SERES Y SUCESOS; [B] ANIMALES Y PLANTAS ESPECIALES.

$\mathrm{N}^{\circ}$ (15), ARCHIVO-TEXTO 4

Motivo: ayu [ a'dzu ]

SUB-TIPO(S): [A.e]; [B.d] (ver ANEXO 1)

Descriptor: "Especie de árbol cuya corteza usan los piasan en tisanas para su consagración" (Armellada y Gutiérrez 1981, pág. 27). Los cocimientos de hojas de ayu elevan los estados de alerta y aclaran la mente. "Manojos de hojas tiernas de este árbol usan también [los piasan] para acompañar el canto e imitar diversos ruidos en sus tenidas" (Armellada y Gutiérrez 1981, pág. 27). El primer ayu estaba dotado del don de la palabra, y poseía conocimientos sobre los beneficios de su savia como calmante y analgésico.

TIPO(S): [A] LOS ORÍGENES: SERES Y SUCESOS.

$\mathrm{N}^{\circ}$ (16), ARCHIVO-TEXTO 4

Motivo: mawariton [ mawari't̃̃n ]

SUB-TIPO(S): [A.b.b1]; [A.b.b2] (ver ANEXO 1)

Descriptor: Son seres escogidos, a quienes "Maware deja oir sus cantos de llamada desde lejos y sume mágicamente en "el ensueño" (Guevara 2011, pág. 235) para trasmitirles la tradición shamánica. Estos mensajeros de Mawari (o Maware), el espíritu dueño del cerro, ejecutan las tareas de enseñanza de la shamanería, y preceden en conocimientos y sabiduría a los shamanes actuales, o piasan o piaimá. Los mawariton son invisibles, aunque pueden adquirir apariencia humana y cambiarla a voluntad; corrientemente agigantan sus estaturas cuando son avistados por la gente común. Los mawariton residen en farallones y cavernas propiedad de Mawari, lugares reservados para la iniciación de los piasan y/o piaimá. 


\section{SECCION C: YE'KWANA}

ARCHIVO-TEXTo 5: Seruhe Ianadi, el inteligente (Arreaza Adam 2005)

Antes el mundo era allá arriba. No había muerte, ni enfermedad, ni guerra. Nadie trabajaba, la comida siempre estaba lista. No había animales, nubes, ni vientos. Sólo luz. Sólo (17) Wanadi 'sol sin atardecer', o el hijo del sol. Por el poder de su luz, la gente estaba siempre alegre, siempre viva, no moría. Todos los pueblos estaban alumbrados. Todos los pueblos quedaban allí. En la Tierra no vivía nadie, sólo la Tierra. Wanadi, el resplandeciente, se dijo un día: "Quiero gente allá abajo. Gente buena como aquí entre nosotros". Entonces hizo otro Wanadi para que bajara a hacer gente en la Tierra. Se llamaba (18) Seruhe Ianadi 'ser inteligente'. Este emisario era espíritu del otro. Era el primer Wanadi que bajaba a la Tierra.

Cuando nació, cortó su ombligo y enterró la placenta. La placenta se pudrió, se la comieron los gusanos. De la placenta podrida nació (19) Odosha, el amo de las sombras y la oscuridad, un hombre malo y envidioso. Cuando nació dijo: --- "Esta Tierra es mía, echaré de aquí a Wanadi. Le haré la guerra". Él enseñó a los demás hombres a mentir, a robar y a matar. Estos últimos, en castigo, fueron convertidos en animales. Así se terminaron los primeros hombres. Desde ese día, cuando nace un niño, no se entierra la placenta. Se guarda en un nido de comejenes, así no entran los gusanos. Así no nace un nuevo Odosha. Esa es la historia antigua.

TIPO(S): [A] LOS ORÍGENES: SERES Y SUCESOS.

$\mathrm{N}^{\circ}(17)$, ARCHIVO-TEXTO 5

MOTIVO: Wanadi [ wãna'oi ]

SUB-TIPO(S): [A.a] (ver ANEXO 1)

DESCRIPTOR: Hijo del sol, y supremo creador. Es un ente inmaterial cuya presencia se encuentra en la luz que todo ilumina. Es el hacedor de todo cuanto existe. Nunca ha bajado a la Tierra; la luz que lo representa llegó hasta ella porque la trajo Seruhe Ianadi, el primer emisario de Wanadi, el hijo del sol.

TIPO(S): LOS ORÍGENES: SERES Y SUCESOS.

$\mathrm{N}^{\circ}(18)$, ARCHIVO-TEXTO 5

MOTIVO: Seruhe Ianadi [ se'ruhعjãna'ði ]

SUB-TIPO(S): [A.a] (ver ANEXO 1); [A.b.b5] Primeros entes terrenales [héroes culturales (humanos imaginarios)]; [A.e] (ver ANEXO 1)

DESCRIPTOR: "El primer Wanadi que bajó a la Tierra. Hizo a la primera gente" (Arreaza-Adam 2005, pág. 70). Al llegar del cosmos, Seruhe Ianadi nació como humano, y usó su inteligencia para hacer los demás hombres y mujeres. Los hizo buenos como él. De una imprevisión de Seruhe Ianadi surgió la envidia y la guerra; y con ellas la maldad rápidamente se apoderó de hombres y mujeres, por lo que debió convertirlos en animales. 
TIPO(S): [A] LOS ORÍGENES: SERES Y SUCESOS.

$\mathrm{N}^{\circ}$ (19), ARCHIVO-TEXTO 5

MOTIVO: Odo'sha [ э'ðっ?ృ ] [Según Civreux (1970), otros nombres que se le da son Kahu y Kahushawa].

SUB-TIPO(S): [A.c]. [A.e] (ver ANEXO 1)

DESCRIPTOR: "El amo de las sombras y la oscuridad. Encarna las fuerzas negativas. Nació de la placenta podrida de Seruhe Ianadi” (Arreaza-Adam 2005, pág. 73). Instauró la maldad en la Tierra, y enseñó a los hombres y mujeres a temer a la muerte. Entre los ye'kwana es el mensajero de un espíritu cosmogónico dueño del cerro, los farallones y las cavernas, y el principal responsable de las desviaciones del comportamiento humano y el causante de alteraciones del orden social.

ARCHIVo-TEXTo 6: Nadei Umadi, el segundo Wanadi (Leyenda de la madre de Wanadi (Arreaza Adam 2005)

Más tarde, Wanadi que nunca sale de (20) Kahuña, pensó: "Quiero saber qué sucede en la Tierra. Quiero que viva allí gente buena". Ahora mandó a (21) Nadei umadi, un segundo emisario. Enseñaría a los hombres que la muerte no existe, que es engaño de Odo'sha. Se sentó, los codos en las rodillas, su cabeza en las manos. Se quedó quieto, pensando, soñando. Así soñó con su madre (22) Kumariawa. Él mismo la hizo, cantando. Con humo de tabaco la hizo. Con el canto de su (23) maraka.

Nadei umadi tenía (24) Huehanna. Lo trajo de Kahuña para hacer gente nueva. Era un gran huevo con la concha dura como piedra. Dentro estaba toda la gente de Wanadi no nacida. "Nacerán", dijo, "y morirán por causa de Odo’sha, luego vivirán por mi poder". Para dar ejemplo, mató a su madre. Para mostrar a Odo'sha su poder, la mató. La sepultó en la tierra y se fue a cazar. Ese fue el primer entierro.

Cuando se fue a cazar dejó a (25) Kudewa cuidando la sepultura. "iQue Odo'sha no se acerque!", dijo, "cuando ella salga, saldrán también los hombres buenos". Kudewa cuidaba la sepultura. Entonces la tierra se movió, y salía de nuevo Kumariawa. Kudewa se volvió loro para avisar. Gritó, gritó, se oía como loro.

TIPO(S): [C] LUGARES ANCESTRALES Y SAGRADOS.

$\mathrm{N}^{\circ}(20)$, ARCHIVO-TEXTO 6

MOTIVO: Kahuña [ ka'hupa ]

SUB-TIPO(S): [C.a] Emplazamiento cósmico (el espacio sideral).

DESCRIPTOR: "Estancia celeste, invisible para los humanos. Lugar sagrado donde reside Wanadi" (Arreaza-Adam 2004, pág. 70). Es para los ye'kwana la fuente de la luz, la sabiduría y la bondad. 
ROMERO-FIGUEROA - MOTIVOS CONTENIDOS EN NARRACIONES...

TIPO(S): [A] LOS ORÍGENES: SERES Y SUCESOS.

$\mathrm{N}^{\circ}(21)$, ARCHIVO-TEXTO 6

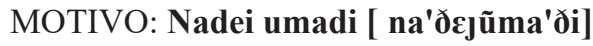

SUB-TIPO(S): [A.a]; [A.b.b5]; [A.e] (ver ANEXO 1)

DESCRIPTOR: "Segundo Wanadi de la Tierra. Hizo a su madre y la mató para resucitarla. Trajo huehanna y, perseguido por Odo'sha, tuvo que esconderlo en una montaña" (Arreaza-Adam 2005, pág. 70). Su tarea al bajar a la Tierra sería mantener haciendo el bien a los hombres y mujeres que traía en huehanna, y prevenir a estos sobre el influjo negativo de Odo'sha, el amo de las sombras y la oscuridad. Ofrecía a la gente la vida aún cuando Odo'sha causara la muerte. El mismo hizo a su madre, y luego la mató y la sepultó, para hacerla resucitar. Con este evento se inician las prácticas funerarias entre los ye'kwana. Nadei umadi quiso demostrar a los hombres y mujeres que traía en huehanna que la muerte era un engaño de Odo'sha. La madre resucitada es quemada por Odo'sha, y desde ese momento la muerte y el miedo imperaron para siempre. Nadei umadi dijo: "Ya la Tierra no es mía, y los hombres morirán", y se marchó dejando oculto el huevo cósmivo.

TIPO(S): [A] LOS ORÍGENES: SERES Y SUCESOS.

$\mathrm{N}^{\circ}$ (22), ARCHIVO-TEXTO 6

MOTIVO: Kumariawa [ kũma'rjawa ]

SUB-TIPO(S): [A.b.b5] (ver ANEXO 1)

DESCRIPTOR: "Madre de Nadei umadi 'el segundo Wanadi', hecha por él mismo" (Arreaza-Adam 2005, pág. 70). Para probarle a la gente temerosa que la muerte era un engaño de Odo'sha ---el amo de las sombras y la oscuridad, Nadei umadi mató a su madre Kumariawa y la enterró, y esta nuevamente brotó viva de la tierra. Es el primer ser terrenal objeto de un entierro, y es el primer muerto que regresa vivo de su tumba. Kamariawa muere nuevamente a manos de Odo'sha, sus cenizas fueron llevadas ante el Supremo Creador y lanzadas a un lago cuyas aguas poseen el poder de la vida eterna. Resucitó una vez más y aún vive en Kahuña.

TIPO(S): [D] OBJETOS MÁGICOS.

$\mathrm{N}^{\circ}(23)$, ARCHIVO-TEXTO 6

MOTIVO: maraka [ ma'raka ]

SUB-TIPO(S): [D.b] Artefactos fabricados (maracas, collares, etc.) que tienen poderes mágicos (para causar y curar enfermedades, etc.). 
DESCRIPTOR: "Instrumento percusivo. Objeto de poder de los huhai o shamanes. Su sonido y magia es producido por los wiriki, o cristales de cuarzo que encierran poderes" (Arreaza-Adam 2005, págs. 75-6). Está formada por un mango y un cuerpo hueco esférico o aovado hecho con una pequeña calabaza seca, relleno con cristales de cuarzo que producen un sonido rítmico según las maneras en que se agite. Los shamanes curan el cuerpo con invocaciones asociadas con los cantos de los wiriki, y protegen el espíritu de cada persona de los influjos malignos de los odo'shakomo, o la gente de Odo'sha.

\section{TIPO(S): [D] OBJETOS MÁGICOS. \\ $\mathrm{N}^{\circ}(24)$, ARCHIVO-TEXTO 6 \\ MOTIVO: Huehanna [ huع'hãn:a ]}

SUB-TIPO(S): [D.a] Objetos cósmicos que forman parte del patrimonio de los creadores.

DESCRIPTOR: "Huevo cósmico que guarda a los seres humanos buenos creados por Wanadi para poblar la Tierra cuando se acabe el mal" (Arreaza-Adam 2005, pág. 69). Nadei umadi 'el segundo Wanadi de la Tierra' extraería los nuevos pobladores buenos luego de derrotar a Odo'sha, el amo de las sombras y la oscuridad. Al no poder librar a la Tierra de la maldad, Nadei umadi lo escondió en una montaña.

\section{TIPO(S): [A] LOS ORÍGENES: SERES Y SUCESOS.}

\section{$\mathrm{N}^{\circ}(25)$, ARCHIVO-TEXTO 6}

\section{MOTIVO: Kudewa [ kuð火'wa ]}

SUB-TIPO(S): [A.b.b2] (ver ANEXO 1)

DESCRIPTOR: "Loro. Avisó a Nadei umadi cuando su madre muerta empezó a brotar de la tierra" (Arreaza-Adam 2005, pág. 72). Hombre que había sido encargado de vigilar la sepultura de Kumariawa, la madre de Nadei umadi, y avisar a este cuando ella empezara a brotar de la tierra al regresar de la muerte. Al empezar a ocurrir le resurrección de Kumariawa, el hombre ansiosamente comenzó a llamar a Nadei umadi. Para hacerle llegar la noticia con más rapidez, se convirtió en loro y voló gritándola.

ARCHIVO-TeXto 7: La leyenda de Hui'io (Civrieux 1970)

La mujer siguió corriendo y llegó al río. La mujer no podía pasarlo. "Bueno”, dijo, "No puedo pasar. El agua va a ser mi camino". Entró en el camino de agua. Nadando, nadando, huía después de robar el huehanna que había escondido Nadei umadi, el segundo Wanadi de la Tierra. La mujer se lo había tragado y lo llevaba en su vientre. Dijo: "Soy dueña del agua, madre de los ríos”, y se transformó en (26) Hui'io, La Gran Serpiente, grandísima. Se mantenía bajo el agua; nadie la veía. En el fondo de un raudal había hecho su casa. Cuando Hui'rio murió a manos de los cazadores enviados por Wanadi ---el hijo del sol, sucedió la Gran Inundación (27) tuna adaihoto, ${ }^{8}$ todos los ríos se salieron de sus madres, y cubrieron toda la Tierra y todos los pueblos. La gente escapó corriendo hasta las cumbres,

\footnotetext{
${ }^{8}[$ tuna $=$ agua; aidaho-to $=$ grandeza-ATRIBUTO $]$
} 
y abismos y grietas, y cuevas. Cuando retrocedieron las aguas, la gente dijo: "Volveremos ahora. Ya no hay peligro". Regresaron entonces y se comieron a la Gran Serpiente, madre de las aguas. Se hartaron de comida y se fueron, uno, otro, otro. El río quedó manchado de sangre, estaba lleno de peces muertos.

Anocheció. Sólo quedó el jaguar (28) Manuwa con su mujer. La mujer miraba la sangre en la laja de la orilla. Encontró dos huevas de peces en lo seco; habían caído sobre la laja, no se habían abierto. "Esos dos se salvaron", dijo la mujer de Manuwa. "Los cuidaré. Les daré calor. Seré su madre". "Bueno", dijo Manuwa, "así tendremos gente". Y poco después nacieron como hombres. (29) Kawao, la esposa de Manuwa, quien a voluntad se convertía en sapo, se sumergió en el río y averiguó que los dos eran hijos de Hui'io y hermanos de los peces.

Así dicen, así cuentan los viejos. Eso es todo.

\section{TIPO(S): [A] LOS ORÍGENES: SERES Y SUCESOS.}

$\mathrm{N}^{\circ}$ (26), ARCHIVO-TEXTO 7

\section{MOTIVO: Hui' io [ hwi?'jo ]}

SUB-TIPO(S): [A.b.b2] (ver ANEXO 1); [A.d] Grandes calamidades (inundaciones); [A.e] (ver ANEXO 1)

DESCRIPTOR: Mujer que hurtó el huennaha o huevo cósmico donde Wanadi guardó los seres humanos buenos que poblarían la Tierra cuando hubiera cesado la maldad. Esta mujer se lo tragó y lo mantuvo en su vientre. Wanadi ordenó la recuperación de huennaha. Al escapar, la mujer se convirtió en una enorme serpiente acuática. Se hizo dueña de todas las aguas. Su persecución y captura dio origen a la primera cacería organizada. Su muerte provocó el desbordamiento de los ríos y la Gran Inundación. Después de su desaparición, Hui'io quedó representada en el arco iris.

\section{TIPO(S): [A] LOS ORÍGENES: SERES Y SUCESOS.}

$\mathrm{N}^{\circ}(27)$, ARCHIVO-TEXTO 7

\section{MOTIVO: tuna adaihoto [ 'tũnaaðaj'hots ]}

SUB-TIPO(S): [A.d] Grandes calamidades (inundaciones).

DESCRIPTOR: Entre los ye'kwana, el término tuna adaihoto (lit.) 'agua grande' hace referencia a la destructiva inundación de los primeros tiempos que condujo al reestablecimiento de la actividad social.

TIPO(S): [A] LOS ORÍGENES: SERES Y SUCESOS.

$\mathrm{N}^{\circ}(28)$, ARCHIVO-TEXTO 7

MOTIVO: Manuwa [ mãnu'wa ]

SUB-TIPO(S): [A.b.b2] (ver ANEXO 1) 
DESCRIPTOR: Hombre con la habilidad de transformarse en jaguar. Lideró el grupo que devoró el cadáver de La Gran Serpiente Hui'io. Después de probar la carne de la serpiente, Manuwa comenzó a comer otros animales, incluidos seres humanos.

TIPO(S): [A] LOS ORÍGENES: SERES Y SUCESOS.

$\mathrm{N}^{\circ}$ (29), ARCHIVO-TEXTO 7

MOTIVO: Kawao [ ka'was ]

SUB-TIPO(S): [A.b.b2]; [A.e] (ver ANEXO 1)

DESCRIPTOR: Mujer con la habilidad de transformarse en sapo. Vivía tanto en la tierra como en el agua. Era la esposa de Manuwa, el hombre-jaguar. Era la dueña del fuego, el cual ocultaba en su vientre y lo escupía para su uso particular. Adopta como hijos los dos hombres que nacieron de dos huevas de pez que sobrevivieron del huehanna, o huevo cósmico, mientras lo portó Hui'io. Estos le robaron el fuego y lo entregaron a los ye'kwana.

ARCHIVO-TEXTo 8: Shikie'mona y Iureke (Civrieux 1970)

Antiguamente, los hombres no conocían el fuego. Comían su comida cruda. Una mujer era dueña del fuego. Lo escondía en su barriga, no lo mostraba a nadie, ni siquiera a su marido. La mujer se llamaba Kawao: se transformaba en sapo cuando quería. Manuwa era el nombre de su marido; cuando salía a cazar, este se volvía jaguar, y comía carne de otros animales y también de gente.

Kawao conocía el secreto: cocinaba sabroso, como ahora nuestras mujeres. Tostaba yuca, mañoco, casabe, cocía frutas, asaba carnes; cuando lo hacía se escondía. Esperaba que Manuwa saliera de cacería. Cuando estaba sola, abría la boca, sacaba el fuego de su vientre, y de prisa lo escupía debajo de la comida. Al terminar, sacaba la lengua, y se tragaba aquel fuego otra vez. Cuando llegaba el marido, su comida estaba lista. Manuwa le preguntaba: “¿Cómo hiciste?" "Con el calor del sol”, contestaba la mujer. Pongo la comida al sol. Así nada más". Aquel jaguar murmuraba: "Bueno". Era ingenuo. Se dejaba engañar por la mujer.

El día que mataron a Hui'io, La Gran Serpiente dueña del agua, Kawao encontró dos huevas de pez que habían sobrevivido, y se las llevó a su casa. Pensó que podría cuidarlas y que al abrir, los peces podrían considerarla como madre. Las puso cerca del fuego para darles calor, y pronto nacieron como peces pero después empezaron a verse como gente. Al mayor lo llamó (30) Shikie'mona y al menor (31) Iureke. Crecieron rápido. Enseguida caminaron, hablaron y comieron. Eran dos hombres poderosos, hermanos de los peces.

Un día, Shikie'mona y Iureke le dijeron al sapo: "Tenemos hambre. Danos casabe. Dinos cómo cocinas". "Nada. No obedecéis", contestó el sapo. Los dos hombres se pusieron de acuerdo: “Cómo haremos?, dijo Shikie’mona. "Descubriremos el secreto”, dijo Iureke. "Me voy a esconder en la casa. Tú saldrás, armarás alboroto afuera. Ella va a creer que estamos jugando. Yo estaré mirando, escondido en el techo. Así vamos a saber".

Shikié'mona salió solo, Iureke se escondió en el techo. Quería descubrir el secreto del sapo. Cogió uno de sus ojos, se lo pegó en la nuca para ver hacia atrás. El sapo oyó el 
alboroto de Shiké'mona. Le pareció que los dos hermanos estaban jugando.

"Bueno, salieron", pensó el sapo. "Ahora están peleando. Voy a hacer casabe. Me apuraré antes de que vuelvan". Miró el budare, y en él estaba el reflejo de Iureke. Entornó los ojos hacia el techo, y allí lo vio.

“¿Qué haces trepado en los horcones? ¡No has salido a jugar con tu hermano! Sal, quiero estar sola porque voy a cocinar”. Iureke le gritó: “¡No puedo, perdí un ojo. No veo bien. No puedo caminar. No voy a mirarte, me voy a voltear hacia el techo". El sapo replicó: "Voltéate pues. No vayas a mirarme". Iureke dijo "Bueno. No veo nada. Cocina ahora que tenemos hambre". Él estaba viendo todo por el ojo de su nuca. Asi engaño al sapo. Este abrió la boca, sopló el fuego, y debajo del budare brilló muchísimo. El ojo de la nuca de Iureke quedó encandilado. No vio nada más.

Poco después, Shikié'mona se acercó a la puerta. La comida estaba lista. El sapo sacó la lengua de prisa, recogió el fuego y se lo tragó. Lo escondió en su barriga.

"Entra", le dijo a Shikié'mona. "Vuélvete", le dijo a Iureke. Este se quitó el ojo encandilado de la nuca, y se lo colocó otra vez en la frente. Cuando vio bien a Shikie'mona, le habló bajito: "Descubrí aquello. Brilla, brilla, como el sol. Es bonito, bonito. Vamos a robarlo". En el momento en que se acercaba el sapo con un cuchillo para cortar la yuca, Iureke se lo arrebató. Le dieron puntapiés, lo apretaron por la barriga y le abrieron la boca. "¡Vomita! ¡Saca aquello de tu barriga!”, gritaban los dos. Empezó el sapo a toser, a escupir, se atragantó, se ahogó. Ahora el fuego se le enredó en su garganta, no podía salir. Los hermanos apretaban y nada. “¡Escúpelo! ¡Vomítalo!”, gritaban, dándole patadas y cuchilladas. Tosía, no podía escupir. La bola de fuego llegaba a su garganta, se hinchaba, se hinchaba, no quería salir. Shikié'mona rajó la boca del sapo. El fuego brotó, quemó el sapo en la espalda, y rodó hasta el suelo, Iureke brincó, lo agarró. A causa de la rajadura de la boca aquel día murió el sapo Kawao. Por eso los sapos de ahora, que son nietos de Kawao, tienen lomos arrugados y bocas anchas, y tienen una bolsa en la garganta que se hincha y deshincha.

Cuando volvía Manuwa, al oir sus pasos por el camino, Shikie'mona y Iureke corrieron a esconder el fuego. Buscaban apresuradamente donde hacerlo. “¿Aquí? ¿Allí? No, allá. Aquí no sirve", decían. Había dos leños detrás de la casa. Iureke escondió la mitad en un leño; Shikié'mona la otra mitad en el otro. Los ye'kwana siempre lo recordamos, cuando queremos fuego nuevo. Tomamos dos leños, frotamos uno contra otro, llamando, llamando, y enseguida el fuego brota, brilla. Al principio del mundo, esos dos hermanos guardaron aquello para nosotros escondiendo el fuego en dos leños. Por eso, la gente come sabroso. Eso es todo.

TIPO(S): [A] LOS ORÍGENES: SERES Y SUCESOS.

$\mathrm{N}^{\circ}$ (30), ARCHIVO-TEXTO 8

MOTIVO: Shikie'mona [ Jikjع?'mona ]

SUB-TIPO(S): [A.b.b2]; [A.e] (ver ANEXO 1) 
DESCRIPTOR: Es el mayor de dos hermanos nacidos del huevo cósmico cuando aún lo portaba Hui'io. Nació pez y era hermano de los peces, pero con el tiempo retornó a su condición humana. Junto con su hermano menor, robó el fuego a su madre Kawao, la mujer-sapo, y lo entregó a los ye'kwana.

\section{TIPO(S): [A] LOS ORÍGENES: SERES Y SUCESOS.}

$\mathrm{N}^{\circ}$ (31), ARCHIVO-TEXTO 8

\section{MOTIVO: Iureke [ ju'reke ]}

SUB-TIPO(S): [A.b.b2]; [A.e] (ver ANEXO 1)

DESCRIPTOR: Es el menor de los hermanos nacidos del huevo cósmico cuando aún lo portaba Hui'io. Nació pez y era hermano de los peces, pero con el tiempo retornó a su condición humana. Junto con su hermano ideó la forma de robar el fuego a su madre Kawao, la mujer-sapo, y lo entregó a los ye'kwana.

\section{Aportes etnoculturales del IM}

El contacto del autor con sus informantes, en algunos casos sostenido durante varios años, contribuyó con su conocimiento de algunos componentes seminales del universo al que han dado forma los kari'ña, pemón y ye'kwana. Destaca entre estos el planteamiento de la existencia de un universo que posee cuatro regiones; de ello surge la tetrarquía de espíritus esenciales que asumen cada una como propia: uno de máximo rango dueño del firmamento y todos los astros, considerado "el abuelo de los abuelos" (Guevara 2011, pág. 240), otro dueño del cerro, otro dueño del agua y otro dueño de la tierra. El precedente señalamiento fue pertinente para la comprensión de los episodios narrados en los archivostexto incluidos en este trabajo. Es relevante apuntar también que aunque los nombres propios de estos espíritus esenciales cambian de una lengua a otra, existe significativa homogeneidad en cuanto a los influjos de lo que estos representan sobre las formas de pensar y actuar de los kari'ña, pemón y ye'kwana.

Los ocho archivos-texto de los que se extrajeron los 31 motivos indizados ponen en evidencia algunos rasgos generales sobre "el origen" de los grupos caribes considerados. Por ejemplo, en todos los tres grupos étnicos, entidades cósmicas bajaron a la Tierra, y a través de descendientes y enviados, crearon a los hombres y las otras criaturas. Las narraciones que detallan estos acontecimientos legendarios a menudo establecen marcos espacio-temporales que incluyen algunas construcciones perifrásticas de tiempo y lugar. Son ilustrativas: "Cuando empezaron los tiempos ..." (Archivo-texto 2, kari'ña), o "Antes, el mundo era allá arriba ..." (Archivo-texto 5, pemón). Por su parte, los ye’kwana llaman (20) Kahuña al lugar invisible de donde fluye la luz, la sabiduría y la bondad. Quizás la más contundente evidencia de la cosmogénesis caribe la ofrece una narrativa referente a los amoríos del sol con una mujer kari'ña que pariría sus hijos gemelos que asegurarían la supervivencia de los hombres guiándolos en sus primeras prácticas agrícolas. El texto dice: “...y [el sol] se la llevó al cielo una vez para amarla. Los nubarrones y las trombas de agua sirvieron de lecho a sus jugueteos, y a sus copulaciones entre las estrellas..." (archivo-texto 2, kari'ña). 
Es asimismo notable en el marco de la cosmogénesis de los pueblos caribes es el hecho de que las entidades creadoras [TIPO [A], subtipo [A.a]] siempre son el sol o un hijo de este, o algunos de sus emisarios: entre los kari'ña, (4) Bedu, la luz inmensa, y el iniciador de la vida de los hombres; entre los ye'kwana, (17) Wanadi 'sol sin atardecer', o el hijo del sol; (18) Seruhe ianadi, el primer emisario de Wanadi ---el hijo del sol; y (21) Nadei umadi, el segundo emisario de Wanadi ---el hijo del sol. En todas las narrativas, la condición celestial del padre es recordada y realzada, y conlleva a la exaltación de las cualidades y méritos de sus descendencias, por ejemplo, sobre los gemelos hijos del sol es destacado que “... resultaron hábiles y afamados cazadores porque por ellos corría sangre de astros" (archivo-texto 2, kari'ña). En otro caso, las referencias a las cualidades de (17) Wanadi 'el hijo del sol' son enaltecidas como sigue a continuación: "Por el poder de su luz, la gente estaba siempre alegre, siempre viva, no moría. Todos los pueblos estaban alumbrados. Todos los pueblos quedaban allí [en (20) Kahuña]". (archivo-texto 5, ye'kwana).

Contrasta el tratamiento dado a la paternidad con el observado en el caso de las madres de las entidades creadoras; estás nunca crían a sus hijos pues son físicamente suprimidas inmediatamente antes o después de estos nacer. Por ejemplo, la mujer kari'ña madre de (6) los dos puidei primigenios, o los gemelos hijos del sol, fue devorada por (5) un tamurü, un ser maléfico con apariencia de anciana, antropófago, que la mató mientras dormía para sacarle los niños del vientre. Aunque les hizo creer a estos que era su madre, esta anciana come gente murió a manos de los dos jóvenes cuando estos descubrieron que planeaba comérselos. Otro ejemplo es el de los jóvenes hermanos (30) Shikie'mona y (31) Iureke, hijos adoptivos de (29) Kawao, la mujer-sapo, a quien estos causaron la muerte para robarle el fuego que escondía en su barriga.

Marca una tendencia significativa entre los grupos estudiados el hecho de que en sus gestas de la creación del mundo tienen activa participación dúos, humanos o no, unidos por estrechos vínculos, en quienes destacan cualidades como las de ser curiosos, habilidosos y habladores, lo que los hace efectivos contribuyentes con el ordenamiento de la vida comunitaria [TIPO: [A], SUBTIPO: [A.e]. Por ejemplo, (6) los dos puidei primigenios, gemelos e hijos del sol, propiciaron los sucesos que condujeron al primer labrantío kari'ña, quienes desde entonces son eficaces cultivadores de la tierra. Asimismo, (30) Shikie'mona y (31) Iureke, dos hermanos, venidos a la Tierra en el huehanna o huevo cósmico, dieron a conocer el fuego entre los ye'kwana, y les enseñaron a hacerlo por fricción de trozos de madera. Entre los pemón se da el caso de los árboles (14) erikawa y (15) ayu, suegro y yerno respectivamente, quienes poseían el don del habla, y que hicieron de sus hojas y ramas piezas imprescindibles dentro en los procedimientos de iniciación en prácticas shamánicas.

El enlace entre los espíritus esenciales y los creadores, y los hombres y mujeres comunes, lo realizan numerosos mensajeros y servidores de los primeros, cuyas actuaciones tienen lugar en escenarios terrenales, aunque son todos entes imaginarios, e inclusive incorpóreos. Estos intermediarios son seres terrenales primigenios del [TIPO [A], subtipo [A.b]], diferenciados según los roles que tienen asignados. Por ejemplo, unos son custodios de las aguas, otros lo son del cerro, los abismos y las cavernas [subtipo [A.b.b1]]: en la tradición kari'ña, son entes que dominan las aguas (2) Amanna y (3) los akodumño, quienes viven en los fondos de ríos y lagunas, hacia donde atraen a 
humanos elegidos para transmitirles sus saberes; entre los pemón, (16) los mawariton son protectores de los ambientes naturales que deben perpetuar la tradición shamánica valiéndose de humanos elegidos.

Estas primeras figuras terrenales se hacen trascendentes y adquieren relevancia cultural por poseer el poder de la transformación física, un rasgo de amplia difusión entre los pueblos aborígenes de la cuenca del Orinoco. En el caso de los kari'ña, pemón y ye'kwana, algunas de estas entidades [TIPO [A], subtipo [A.b.b2]] son capaces a voluntad de cambiar temporalmente de apariencia y tamaño, otros simplemente se metamorfosean. Por ejemplo, cambian mágicamente (3) los akodumño (de hombres a serpientes acuáticas), (16) los mawariton (agigantan su estatura corporal), (25) Kudewa (de hombre a loro), (26) Hui'io (de mujer a serpiente acuática), (28) Manuwa (de hombre a jaguar), y (29) Kawao (de mujer a sapo). Han sufrido metamorfosis (30) Shikie'mona y (31) Iureke (ambos nacidos peces y progresivamente transformados en humanos).

Algunos de los primeros seres terrenales tuvieron cortas participaciones en los sucesos narrados sobre los orígenes de los pueblos caribes. Las narraciones revelan que en sus breves tránsitos por la Tierra crearon entre los hombres y mujeres comunes expectativas que los últimos esperan sean satisfechas. En el caso de los ye'kwana, por ejemplo, (18) Seruhe ianadi y (21) Nadei umadi, el primero y segundo emisarios de Wanadi ---el hijo del sol, aún hacen esfuerzos por erradicar la maldad imperante en la tierra, y (22) Kumariawa, la madre de este último, aguarda todavía la derrota de la muerte para hacer realidad la promesa de la vida eterna. La identificación de los hombres y mujeres ye'kwana del presente con esta lucha por el bien y por la vida de Seruhe ianadi, Nadei umadi y Kumariawa, los ha llevado a humanizarlos y a honrarlos como héroes [TIPO: [A], SUBTIPO: [A.b.b5].

Igualmente, en las narraciones sobre los orígenes que han sido considerados en este estudio se escuchan pasajes protagonizados por entes negativos que confrontan a aquellos otros que se encuentran responsabilizados por los creadores con la construcción de mundos de bondad y abundancia. Todos ellos usan estrategias consonantes con sus roles en el marco de la pugna entre el bien y el mal [TIPO [A], SUBTIPO [A.c]. Destacan entre los kari'ña (5) el tamurü (o los tamurümño o tarümño), o come-gente(s); entre los pemón, (7) Mochima, el águila gigante come-hombres; y entre los ye'kwana (19) Odo'sha, el amo de las sombras y la oscuridad, y el principal responsable de las desviaciones de la conducta humana. Los tres entes precitados coinciden en ser dominados por el espíritu cosmogónico esencial dueño del cerro, y los farallones y las cuevas, sobre quien también recae la potestad de escoger aquellos que han de perpetuar las prácticas beneficiosas de la curación y la protección de la familia y la comunidad.

Abundan en las narraciones tramas que exponen eventos sobre los cuales se modelan costumbres y prácticas de vida de los hombres y mujeres creados, o enviados, para poblar la Tierra. Son diversos los que contribuyen con el ordenamiento de la vida humana [TIPO [A], SUBTIPO [A.e]], específicamente hechos relacionados con el inicio del arte de la cacería con curare (Strychnos guianensis), de la cacería grupal organizada, la actividad agrícola, la práctica shamanística, los ritos funerarios y las desviaciones del comportamiento humano, así como la manera en que el fuego llegó a tener un uso general.

En muchos de los episodios interactúan seres humanos con plantas y animales con dotes especiales. Es pertinente señalar que entre los animales destacan las aves, de las 
cuales ---desde los primeros tiempos--- ha dependido la sustentación de la vida de los hombres. Por ejemplo, en las acciones preliminares que conllevaron al conocimiento del curare intervienen (8) Maruk, una gallineta de monte, (9) el ayiten, un minúsculo pájaro carpintero, y (10) kurachi, el ruiseñor de montaña. Las tres ---capaces de comunicarse con los hombres, son aves amistosas que saben secretos [TIPO [B], SUBTIPO [B.a]]; todas ellas proporcionaron a los pemón detalles sobre la planta del curare, sus propiedades y sus posibles usos en la cacería.

En el mismo marco del inicio del arte de la caza con dardos de curare, al proceso de desarrollo de la cerbatana, o instrumento para dispararlos, hicieron aportes animales y plantas que son de ayuda para las actividades agrícolas y de elaboración de instrumentos [TIPO [B], SUBTIPO [B.b]]: (12) patiri, o lombrices de tierra gigantes que fertilizan la tierra de cultivo, y (13) sanwoto, tipo de planta de bambú (Arthrostylidium schomburgkii) indispensable para la fabricación de las cerbatanas, pues suplen las cañas para sus cañones. Las primeras cerbatanas provinieron de la tierra dónde fue enterrado (7) Mochima, el águila sanguinaria come-gentes; de sus plumas brotó el patiri, y allí mismo creció profusamente el bambú.

Por otra parte, en las acciones de trasmisión de la tradición shamánica poseen participaciones primordiales algunas especies vegetales que proporcionan recursos para el trabajo de los curanderos [TIPO [B], SUBTIPO [B.d]], como son (14) el erikawa, árbol con propiedades alucinógenas y eméticas, y (15) el ayu, árbol para infusiones calmantes y analgésicas. Señalan los textos que los especímenes primigenios de estos dos árboles eran suegro y yerno respectivamente, y tenían el don de la palabra. Cuentan los narradores que en medio de una querella familiar, estos revelaron secretos de valor etnobotánico. Desde entonces los shamanes han utilizado hojas y ramas de erikawa y ayu durante sus ritos de iniciación, y para algunas de sus prácticas curativas.

En cuanto al episodio que culmina con el uso general del fuego por parte de todos los hombres debe traerse a consideración la mención que en una de las narraciones ye'kwana tiene (29) Kawao, la mujer que se convertía en sapo y que para su uso exclusivo escondía el fuego en su barriga. Este le fue robado por sus hijos de crianza, el mayor (30) Shikie'mona y el menor (31) Iureke. Ha de destacarse que entre los grupos caribes estudiados, el sapo es un animal de notable figuración en asociación con las proezas de las duplas de hermanos gemelos, o no, mencionados en las gestas de la creación del mundo. Otro caso de presencia de un sapo es parte de la historia de los kari'ña; en este caso se trata de un enorme batracio que aporta la leche para cocinar las sipipas con que (5) el tumurü, o anciana come-gente, alimenta a (6) los dos puidei primigenios hijos gemelos del sol.

Existen también coincidencias en la materia relativa a algunos objetos mágicos, particularmente los fabricados para el ejercicio de las actividades shamanisticas [TIPO [D], SUBTIPO [D.d]]. Entre los kari'ña, pemón y ye'kwana es recurrente la referencia a (23) la maraka como objeto de poder para los puidei kari’ña, los piasan pemón, y los huhai ye'kwana. En todos los tres casos la magía de este instrumento de percusión, proviene de los wiriki, o cristales de cuarzo, encerrados dentro de la pequeña calabaza seca con mango de madera, movida rítmicamente por los shamanes. 


\section{ROMERO-FIGUEROA - MOTIVOS CONTENIDOS EN NARRACIONES...}

\section{Referencias}

Armellada, Césareo de (1973). Taurón pantón II. Caracas: Universidad Católica Andrés Bello.

Armellada, Césareo de y C. Bentivenga (1980). Literatura indígena venezolana. Caracas: Monte Ávila Editores.

Armellada, Césareo de y M. Gutierrez (1981). Diccionario pemón. Caracas: Publicaciones Corpoven.

Arreaza Adam, Henrietta (2005). Watunna. La canción del mundo. Cosmogonía ye'kwana. Mérida, Venezuela: Siembraviva Ediciones.

Civrieux, Marc de (1970). Watunna: mitología maquiritare. Caracas: Monte Ávila Editores.

Civrieux, Marc de (1976). Los caribes y la conquista de la Guyana española (Etnohistoria kari'ña). Caracas: UCAB.

Ferro, Roberto (20 de julio 2014). Pueblo kari'ña --- Textos y fotos [Mensaje en un blog]. http: //textosyfotos.blogspot.com>2014/07>pueblo-karina.html

Guevara, José (2011). La identidad cero (La dinastía cero). https://books.google.co.ve/ books?id $=$ XmXvAgAAQBAJ\&dq $=$ La + identidad + cero + por + Jos $\% C 3 \% A 9+$ A. + Guevara\&source $=$ gbs navlinks_s

Honti, János (1937). A Mese világa. Budapest: Pantheon.

Instituto Nacional de Estadística (INE)-Venezuela (2011). XIV Censo Nacional de Población y Vivienda. http://www.ine.gov.ve/CENSO2011/

Romero-Figueroa, Andrés (2011). El sistema ergativo de las caribes del norte, ¿muestra signos de debilitamiento? En Andrés Romero-Figueroa (coord.), Lenguas indigenas de América: morfología y sintaxis, pp. 116-140. Caracas: Universidad Católica Andrés Bello.

Romero-Figueroa, Andrés (2013a). Deixis y anáfora en pemón, ye'kwana y panare (caribes del norte). En Ana Fernández; Marisa Censabella; y Marisa Malvestitti (eds.), Lingüistica Amerindia: contribuciones y perspectivas, pp. 115-126. Buenos Aires: Universidad de Buenos Aires.

Romero-Figueroa, Andrés (2013b). El originario sistema de patrones ergativo de las lenguas caribes del norte. UniverSOS 10: 11-34. https://dialnet.unirioja.es/servlet/revista?codigo $=8164$

Romero-Figueroa, Andrés (2013c). Análisis tipológico funcional de los comparativos en las lenguas caribes del norte. Boletín de Lingüistica UCV 25(39-40): 187-216.

https://dialnet.unirioja.es/servlet/articulo? codigo $=4557150$

Romero-Figueroa, Andrés (2015). Cláusulas ergativas y no ergativas en ye'kwana (caribe del norte). LIAMES Linguas Indigenas Americanas 15(1): 113-124. https://doi.org/10.20396/liames.v15i1.8641498

Thompson, Stith (1977 [1946]). The folktale. New York: Holt, Rinehart and Winston.

Thompson, Stith (1955-1958). Motif-Index of folk literature. Bloomington: Indiana University Press.

Valory, Dale (1967). Folklore of the Fuego-Patagonian peoples: Annotated bibliography. Behavior Science Notes 2(3): 175-202. 


\section{ROMERO-FIGUEROA - MOTIVOS CONTENIDOS EN NARRACIONES...}

Wilbert, Johannes (1970). Folk literature of the Warao Indians: Narrative material and Motif Content. Los Angeles: University of California, Latin American Center Publications.

Wilbert, Johannes (1975). Folk-Literature of the Selknam Indians. Los Angeles: University of California, Latin American Center Publications. 


\section{ANEXO 1}

TIPOS Y SUB-TIPOS DE MOTIVOS PROPUESTOS POR THOMPSON (siguen la nomenclatura de Thompson, ajustada de acuerdo con las particularidades etnolingüísticas de los grupos considerados)

A. LOS ORÍGENES: SERES Y SUCESOS.

a. Creadores [entidades superiores cosmogónicas/cósmicas/celestes (el padre sol, los hijos del sol y la luna, las constelaciones, etc.)]

b. Primeros entes terrenales

b.1. Entes custodios originales del cielo, el agua, la tierra y/o el fuego

b.2. Entes que se transforman mágicamente

b.3. Animales surgidos de partes de seres humanos

b.4. Descendientes de las relaciones entre astros y animales con seres humanos

b.5. Héroes culturales (humanos imaginarios)

c. Entes malevolentes (la presencia de las fuerzas negativas, la lucha entre el bien y el mal, y entre el débil y el fuerte)

d. Grandes calamidades (inundaciones, sequías, hambrunas, guerras, etc.)

e. Ordenamiento de la vida humana [el uso general del fuego, la fabricación de la primera embarcación (o medio de transporte), el inicio del arte de la cacería con dardos envenenados, el inicio de la cacería grupal organizada, el aprendizaje de la navegación, el inicio de la actividad pesquera o agrícola, el inicio de la práctica shamánistica, el inicio del rito funerario, el inicio de las desviaciones del comportamiento humano, etc.].

B. ANIMALES Y PLANTAS ESPECIALES

a. Animales amistosos que saben secretos

b. Animales y plantas que ayudan en el trabajo (agricultura, caza, pesca, recolección, etc.)

c. Animales vistosos que sirven de señuelos

d. Plantas y animales proveedoras de recursos esenciales. 
C. LUGARES ANCESTRALES Y SAGRADOS.

a. Emplazamiento cósmico (el espacio sideral)

b. Referentes topográficos en la Tierra (montañas, cascadas, ríos, etc.)

c. Productos naturales provenientes del suelo y subsuelo (rocas, metales, etc.)

D. OBJETOS MÁGICOS

a. Objetos cósmicos que forman parte del patrimonio de los creadores

b. Artefactos fabricados (maracas, collares, etc.) que tienen poderes mágicos (para causar y curar enfermedades, etc.)

E. MUERTE

a. Sepelios/exequias

b. Resurrección y re-encarnación; regreso de la muerte

c. Fantasmas y otras apariciones

d. Encantamientos y hechizos

e. Cantos mágicos (ensalmes)

F. ACONTECIMIENTOS MARAVILLOSOS

a. Viajes cósmicos

b. Lugares paradisiacos/infernales

c. Fenómenos de la naturaleza (gigantes, enanos, etc.)

G. PRUEBAS DE CERTIDUMBRE, INTELIGENCIA Y FORTALEZA (EN BUENA LID O CON TRUCOS)

a. Competencias y torneos (sabiduría y torpeza, uso de armas y otros objetos, etc.)

b. Enfrentamientos físicos (luchas cuerpo a cuerpo)

c. Comprobación de la verdad 
H. FUTURO
a. Promesas
b. Profecías
c. Maldiciones y castigos

I. DESTINO Y AZAR
a. Hechos azarosos favorables
b. Elementos intermediarios para la suerte

J. RECOMPENSAS Y CASTIGOS
a. Acciones premiadas y sus ejecutores y/o recipiendarios
b. Acciones castigadas y sus ejecutores y/o recipiendarios

K. SEXO
a. Amoríos
b. Vida conyugal
c. Relaciones sexuales ilícitas
d. Concepción y nacimiento

L. HUMOR

a. Humor a causa de defectos físicos 
MOTIVOS INDIZADOS ORDENADOS POR TIPOS Y SUB-TIPOS (siguiendo la nomenclatura propuesta por Thompson, ajustada de acuerdo con las particularidades etnolingüísticas de los grupos considerados)

TIPO: [A] LOS ORÍGENES: SERES Y SUCESOS.

SUBTIPO: [A.a] Creadores [entidades superiores cosmogónicas/cósmicas/celestes (el padre sol, los hijos del sol y la luna, las constelaciones, etc.)]

\begin{tabular}{|l|l|}
\hline kari'ña & (4) Bedu: 'La luz inmensa', el iniciador de la vida de los hombres. \\
\hline & $\begin{array}{l}\text { (17) Wanadi: 'sol sin atardecer', el hijo del sol, y supremo creador. Nunca } \\
\text { ha bajado a la Tierra. La luz que lo representa llegó a ella traída por el } \\
\text { primero de sus varios emisarios. }\end{array}$
\end{tabular}

(18) Seruhe ianadi: El primer emisario de Wanadi, el hijo del sol. Hizo ye'kwana hombres buenos, y pobló el mundo, pero cuando estos se hicieron malos los hizo desaparecer convirtiéndolos en animales.

(21) Nadei umadi: El segundo emisario de Wanadi, el hijo del sol. Cargó en un huevo cósmico nuevos hombres buenos para poblar la Tierra, pero no lo hizo al no poder acabar con la maldad. Se retiró luego de ocultar su carga en una montaña.

\section{TIPO: [A] LOS ORÍGENES: SERES Y SUCESOS.}

SUBTIPO: [A.b.b1] Primeros entes terrenales (entes custodios del cielo, el agua, la tierra, y/o el fuego.

\begin{tabular}{|l|l|}
\hline \multirow{5}{*}{ kari'ña } & $\begin{array}{l}\text { (1) Akodumo: Espíritu dueño del agua que domina sobre todos los seres } \\
\text { acuáticos de este mundo. }\end{array}$ \\
\cline { 2 - 2 } & $\begin{array}{l}\text { (2) Amanna: Mujer hermosa cuya actividad ocurre en el mundo sub- } \\
\text { acuatico, lugar secreto de ubicación desconocida para los hombres } \\
\text { ordinarios. Atrae hombres escogidos para convertirlos en akodumño, o } \\
\text { custodios de las aguas. Es instructora de fórmulas mágicas, y proveedora } \\
\text { de talismanes y otros objetos que protegen contra diversos males. }\end{array}$ \\
\cline { 2 - 2 } & $\begin{array}{l}\text { (3) akodumño: Mensajeros o servidores de Akodumo, el espíritu dueño } \\
\text { del agua. Estos deben legar sus poderes mágicos a hombres y mujeres } \\
\text { comunes escogidos. }\end{array}$ \\
\hline \multirow{2}{*}{ pemón } & $\begin{array}{l}\text { (16) mawariton: Mensajeros o servidores de Mawari (o Maware), } \\
\text { el espíritu dueño del cerro, los farallones y las cuevas. Son humanos } \\
\text { escogidos para que trasmitan la tradición shamánica. }\end{array}$ \\
\hline
\end{tabular}


TIPO: [A] LOS ORÍGENES: SERES Y SUCESOS.
SUBTIPO: [A.b.b2] Primeros entes terrenales (entes que se transforman mágicamente)

\begin{tabular}{|l|l|}
\hline & (3) akodumño: Mensajeros y servidores de Akodumo, el espíritu dueño
\end{tabular} kari'ña del agua. Son humanos en lo invisible, y adquieren formas de gigantescas

serpientes de agua, o anacondas, cuando son avistados por los hombres comunes.

\begin{tabular}{|l|l|}
\hline & (16) mawariton: Mensajeros o servidores de Mawari (o Maware),
\end{tabular}

pemón el espíritu dueño del cerro. Son escogidos para trasmitir la tradición

shamánica. Son invisibles, pero pueden hacerse corpóreos y suelen agigantarse cuando son avistados por la gente común.

(25) Kudewa: Hombre encargado por Nadei umadi, el segundo emisario de Wanadi, el hijo del sol, de la vigilancia de la sepultura de su madre, y de avisarle sobre su resurrección. Para agilizar esta tarea, se transformó en loro, y voló gritando y alertando a todos sobre el suceso.

(26) Hui'io: Mujer que robó a Nadei umadi, el segundo emisario de Wanadi ---el hijo del sol, el huevo cósmico donde se encontraban guardados los seres humanos buenos que poblarían la Tierra. Se convirtió en La Gran Serpiente habitante de un remanso de un río. Mantuvo el huevo en su vientre hasta que fue cazada y muerta.

(28) Manuwa: Hombre con la habilidad de transformarse en jaguar. Lideró el grupo de animales que devoró La Gran Serpiente Hui'io, y ye'kwana después que probó su carne, comenzó a comerse a los demás animales y a los seres humanos.

(29) Kawao: Mujer que se transformaba en sapo. Era la dueña del fuego, el cual ocultaba en su vientre y escupía solo para su uso particular.

(30) Shikie'mona: El mayor de dos hermanos nacidos del huevo cósmico cuando aún lo portaba La Gran Serpiente Hui'io. Nació como pez, pero se transformó en humano. Junto con su hermano Iureke robó el fuego a su madre adoptiva Kawao ---la mujer-sapo.

(31) Iureke: El menor de dos hermanos nacidos del huevo cósmico cuando aún lo portaba La Gran Serpiente Hui'io. Nació como pez, pero se transformó en humano. Junto con su hermano Shikie'mona robó el fuego a su madre adoptive Kawao ---la mujer-sapo.

\section{TIPO: [A] LOS ORÍGENES: SERES Y SUCESOS.}

SUBTIPO: [A.b.b4] Primeros entes terrenales (descendientes de las relaciones entre astros y animales con seres humanos). 


\begin{tabular}{|c|c|}
\hline kari’ña & $\begin{array}{l}\text { (6) puidei: Benefactores de la vida cotidiana y sanadores de enfermos, } \\
\text { atributos otorgados por el espíritu dueño del cerro, y los farallones y } \\
\text { cavernas. Los dos primeros puidei fueron gemelos, y tenían sangre de } \\
\text { astros por ser hijos del sol en una mujer kari'ña. Estos puidei poseen "almas } \\
\text { celestes" (Guevara, 2011, pág. 248), lo que les concede el privilegio de } \\
\text { vivir en el cielo y en la tierra. }\end{array}$ \\
\hline \multirow{2}{*}{\multicolumn{2}{|c|}{$\begin{array}{l}\text { TIPO: [A] LOS ORÍGENES: SERES Y SUCESOS. } \\
\text { SUBTIPO: [A.b.b5] Primeros entes terrenales [héroes culturales (humanos imaginarios)]. }\end{array}$}} \\
\hline & \\
\hline \multirow{3}{*}{ ye'kwana } & $\begin{array}{l}\text { (18) Seruhe ianadi: El primer emisario de Wanadi, el hijo del sol. } \\
\text { Convirtió en animales a los primeros pobladores de la Tierra cuando estos } \\
\text { se hicieron malos. Su lucha contra la maldad aún no ha finalizado. }\end{array}$ \\
\hline & $\begin{array}{l}\text { (21) Nadei umadi: El segundo emisario de Wanadi, el hijo del sol. Trajo } \\
\text { en el huevo cósmico nuevos hombres buenos que poblaran la Tierra, pero } \\
\text { no lo hizo al no poder erradicar la maldad. Su lucha contra la maldad aún } \\
\text { prosigue. }\end{array}$ \\
\hline & $\begin{array}{l}\text { (22) Kumariawa: Madre de Nadei umadi, el segundo emisario de Wanadi, } \\
\text { el hijo del sol. Fue hecha por su hijo, y quemada por Odo'sha, el amo de } \\
\text { las sombras y la oscuridad. Las cenizas de Kumariawa fueron llevadas } \\
\text { ante Wanadi, y lanzadas por este a un lago cuyas aguas tienen el poder de } \\
\text { la vida eterna. Fue resucitada por segunda vez, y aun vive en kahuña. Ha } \\
\text { de legar a los ye'kwana la vida eterna cuando solo haya hombres buenos. }\end{array}$ \\
\hline \multicolumn{2}{|c|}{ TIPO: [A] LOS ORÍGENES: SERES Y SUCESOS. } \\
\hline \multicolumn{2}{|c|}{$\begin{array}{l}\text { SUBTIPO: [A.c] Entes malevolentes (la presencia de las fuerzas negativas, la lucha } \\
\text { entre el bien y el mal, y entre el débil y el fuerte). }\end{array}$} \\
\hline kari’ña & $\begin{array}{l}\text { (5) tamurünmño } \sim \text { tarünmño } \sim \text { tamurü: Mensajeros o servidores de } \\
\text { Mawari (o Maware), el espíritu que domina el cerro, los farallones y las } \\
\text { cavernas. Los tamurümño son dueños de la vida y de la muerte, “... son } \\
\text { hombres y mujeres poderosos y ambivalentes, amorales” (Guevara 2011, } \\
\text { pág. 243). Son antropófagos, y pueden causar enfermedades. }\end{array}$ \\
\hline pemón & $\begin{array}{l}\text { (7) Mochima: Águila gigantesca y sanguinaria que comía seres humanos. } \\
\text { Surgió del corazón de una danta que el suegro, un mensajero del espíritu } \\
\text { dueño del cerro, y los farallones y las cuevas, había obsequiado a su yerno } \\
\text {---el espíritu poseedor del rayo. El corazón de Mochima quedó recubierto } \\
\text { de la roca del recipiente en que había sido resguardado; eso lo hizo un } \\
\text { depredador invulnerable. }\end{array}$ \\
\hline
\end{tabular}




\begin{tabular}{|l|l|}
\hline ye'kwana & $\begin{array}{l}\text { (19) Odo'sha: Amo de las sombras y la oscuridad. Es el principal } \\
\text { responsable de las desviaciones de comportamiento humano. Es un } \\
\text { mensajero y servidor negativo (sus acciones contrastan con las de los } \\
\text { representantes benefactores y protectores) del espíritu dueño del cerro, y } \\
\text { los farallones y cuevas. }\end{array}$ \\
\hline TIPO: [A] LOS ORÍGENES: SERES Y SUCESOS. \\
SUBTIPO: [A.d] Grandes calamidades (inundaciones).
\end{tabular}




\begin{tabular}{|c|c|}
\hline \multirow[b]{5}{*}{ pemón } & $\begin{array}{l}\text { (7) Mochima: [El inicio del arte de la caza con curare (strychnos } \\
\text { guanensis). Su muerte trajo acciones relacionadas con la construcción de } \\
\text { la cerbatana para cazar con dardos envenenados con curare]. }\end{array}$ \\
\hline & $\begin{array}{l}\text { (8) Maruk: [El inicio del arte de la caza con curare (strychnos guanensis)]. } \\
\text { Gallineta de monte que conocía el curare, y le explicó sus efectos a los } \\
\text { hombres, guiándolos en el reconocimiento de la planta de la cual se extrae. }\end{array}$ \\
\hline & $\begin{array}{l}\text { (9) ayiten: [El inicio del arte de la caza con curare (strychnos guanensis). } \\
\text { El más pequeño de los especímenes de pájaro carpintero que demostró a } \\
\text { los hombres la eficacia del veneno del curare comiendo algunas hojas de } \\
\text { la planta. Cayó en letargo, pero fue revivido por los hombres. }\end{array}$ \\
\hline & $\begin{array}{l}\text { (10) kurachi: [El inicio del arte de la caza con curare (strychnos } \\
\text { guanensis)]. Ruiseñor de montaña que con sus cantos advirtió a los } \\
\text { hombres por donde debían flechar a Mochima, el águila come-gente. } \\
\text { Su participación en la muerte de este último lo relaciona con los hechos } \\
\text { conducentes a la construcción de la cerbatana para cazar con dardos } \\
\text { untados con curare. }\end{array}$ \\
\hline & $\begin{array}{l}\text { (12) patiri: [El inicio del arte de la caza con curare (strychnos guanensis)]. } \\
\text { Lombrices de tierra de gran tamaño con origen en las plumas de Mochima, } \\
\text { el águila como-gente. Este último fue enterrado en las tierras de los } \\
\text { madonkon, cuya fertilidad por efectos de estas lombrices las hace ricas en } \\
\text { plantas de bambú (arthrostylidium schomburgkii), imprescindibles para la } \\
\text { fabricación de cerbatanas para la caza con curare. }\end{array}$ \\
\hline & $\begin{array}{l}\text { (13) sanwoto: [El inicio del arte de la caza con curare (strychnos } \\
\text { guanensis)]. Cepas de bambú (arthrostylidium schomburgkii) abundantes } \\
\text { en la tierra de los madonkon, dada su fertilidad por la riqueza orgánica que } \\
\text { el patiri, o las lombrices de tierra gigantes, dan al suelo. De estas cepas } \\
\text { se cortan las dos cañas para construir cerbatanas, instrumentos de cacería } \\
\text { consistentes de una cubierta cilíndrica y de un cañón de menor diámetro, } \\
\text { que permite con soplidos disparar a las presas dardos envenenados. }\end{array}$ \\
\hline & $\begin{array}{l}\text { (14) erikawa: [El inicio de la práctica shamanística]. Árbol primigenio } \\
\text { con el don de la palabra, cuyas hojas cocidas tienen efectos eméticos } \\
\text { y alucinógenos visibles en los rituales de iniciación de los curanderos. } \\
\text { Erikawa advirtió sus cualidades a otro árbol primigenio llamado ayu, } \\
\text { también con comportamiento humano, cuyas hojas curan los vómitos y } \\
\text { aclaran la mente. }\end{array}$ \\
\hline & $\begin{array}{l}\text { (15) ayu: [El inicio de la práctica shamanística]. Árbol primigenio con } \\
\text { comportamiento humano, cuyas ramas en la shamanística son usadas para } \\
\text { emitir ruidos que alejan los espíritus malignos. De sus hojas los shamanes } \\
\text { extraen zumos para aliviar toda clase de dolencias. Los pemón de la } \\
\text { actualidad aprecian mucho el árbol de ayu, y los mayores recomiendan a } \\
\text { los más jóvenes hacerse remedios con este y no con el erikawa. }\end{array}$ \\
\hline
\end{tabular}




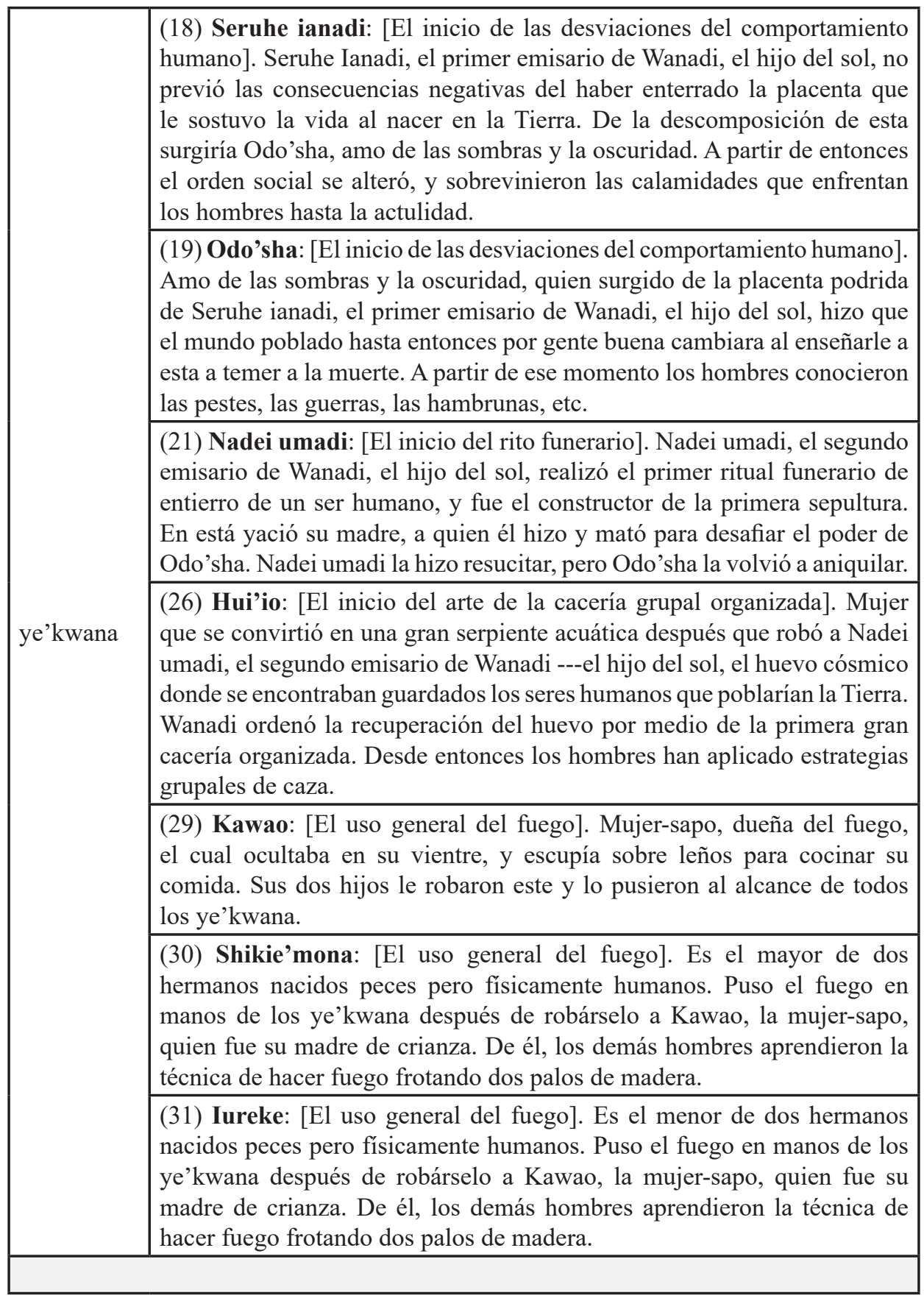




\section{TIPO: [B] ANIMALES Y PLANTAS ESPECIALES. \\ SUBTIPO: [B.a] Animales amistosos que saben secretos.}

\begin{tabular}{|l|l|}
\hline pemón & $\begin{array}{l}\text { (8) Maruk: Es una gallineta de monte que reveló a los hombres las } \\
\text { propiedades tóxicas de la savia de la planta de curare porque le habían } \\
\text { contado que uno de sus abuelos había comido sus hojas y flores. El sabor } \\
\text { amargo de la carne de la gallineta de monte, según los pemón, es una } \\
\text { consecuencia de haber probado el curare. }\end{array}$ \\
\hline $\begin{array}{l}\text { (9) ayiten: Variedad más pequeña de los pájaros carpinteros que demostró } \\
\text { a los hombres los efectos tóxicos de la planta de curare comiendo sus } \\
\text { hojas. Cayó envenenado dos veces, pero los comejenes lo revivieron } \\
\text { cubriéndolo con hojas de tabaco. }\end{array}$ \\
\hline $\begin{array}{l}\text { (10) kurachi: Referencia para el ruiseñor de montaña, pájaro común y } \\
\text { abundante en la selva amazónica, cuyo canto armonioso seduce a los } \\
\text { hombres. Con sus repetidos trinos advirtió a los cazadores que flecharan a } \\
\text { Mochimá por la espalda, pues por el pecho las flechas no entrarían en su } \\
\text { corazón por estar recubierto con rocas. }\end{array}$ \\
\hline TIPO: [B] ANIMALES Y PLANTAS ESPECIALES.
\end{tabular}

SUBTIPO: [B.b] Plantas y animales que ayudan en el trabajo (agricultura, caza, pesca, recolección, etc.).

\begin{tabular}{|l|l|}
\hline \multirow{2}{*}{ pemón } & $\begin{array}{l}\text { (12) patiri: Variedad de lombrices de tierra gigantes que crecieron de las } \\
\text { plumas de Mochima, una vez este fue enterrado. Este tipo de lombrices } \\
\text { de tierra conceden mucha fertilidad a los suelos ribereños de la cuenca del } \\
\text { Orinoco. }\end{array}$ \\
\hline \multicolumn{1}{|l}{ TIPO: [B] ANIMALES Y PLANTAS ESPECIALES. } \\
SUBTIPO: [B.d] Plantas y animales proveedores de recursos esenciales.
\end{tabular}




\begin{tabular}{|c|c|}
\hline \multicolumn{2}{|c|}{$\begin{array}{l}\text { TIPO: [C] LUGARES ANCESTRALES Y SAGRADOS. } \\
\text { SUBTIPO: [C.a] Emplazamiento cósmico (el espacio sider }\end{array}$} \\
\hline ye'kwana & $\begin{array}{l}\text { (20) Kahuña: "Estancia celeste, invisible para los humanos. Lugar donde } \\
\text { reside Wanadi" (Arreaza-Adam 2004, pág. 70). Es para los ye'kwana la } \\
\text { fuente de luz, sabiduría y bondad. }\end{array}$ \\
\hline \multicolumn{2}{|c|}{ TIPO: [C] LUGARES ANCESTRALES Y SAGRADOS. } \\
\hline \multicolumn{2}{|c|}{ SUBTIPO: [C.b] Referentes topográficos en la Tierra (montañas, cascadas, ríos, etc.). } \\
\hline pemón & $\begin{array}{l}\text { (11) tierra de los madonkon: Término con que los pemón se refieren a } \\
\text { los ye'kwana, grupo étnico de filiación caribe, sub-rama norte, que habita } \\
\text { en una zona que se extiende desde el río Ventuari hasta el río Paragua, en } \\
\text { la Guayana venezolana. Es una región selvática extensa, al oeste de las } \\
\text { tierras de los pemón. }\end{array}$ \\
\hline \multicolumn{2}{|c|}{ TIPO: [D] OBJETOS MÁGICOS. } \\
\hline \multicolumn{2}{|c|}{$\begin{array}{l}\text { SUBTIPO: [D.b] Artefactos fabricados (maracas, collares, etc.) que tienen poderes } \\
\text { mágicos (para causar y curar enfermedades, etc.). }\end{array}$} \\
\hline ye'kwana & $\begin{array}{l}\text { (23) maraka: "Instrumento percusivo. Objeto de poder de los huhai o } \\
\text { shamanes. Su sonido y magia es producido por los wiriki, o cristales de } \\
\text { cuarzo que encierran poderes" (Arreaza-Adam } 2005 \text { págs. } 75-6 \text { ). }\end{array}$ \\
\hline \multicolumn{2}{|c|}{ TIPO: [D] OBJETOS MÁGICOS. } \\
\hline \multicolumn{2}{|c|}{ SUBTIPO: [D.a] Objetos cósmicos que forman parte del patrimonio de los creadores. } \\
\hline & $\begin{array}{l}\text { (24) Huehanna: "Huevo cósmico que guarda a los seres humanos } \\
\text { buenos creados por Wanadi para poblar la Tierra cuando se acabe el mal" } \\
\text { (Arreaza-Adam } 2005 \text { pág. 69). }\end{array}$ \\
\hline
\end{tabular}

Recebido:16/4/2020

Versão revista e corrigida: 7/6/2020

Aceito: $10 / 7 / 2020$ 